\title{
RECONOCIMIENTOS, RESPUESTAS Y GLOSAS
}

\author{
Francisco Laporta \\ Universidad Autónoma de Madrid
}

\section{PALABRAS DE AGRADECIMIENTO}

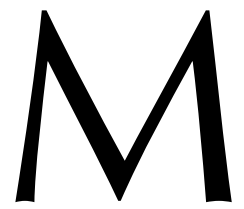

uchos sabéis que soy persona más bien solitaria y poco vanidosa (aunque decir esto pueda verse también como un pequeño acto de vanidad). No sé muy bien a qué se deben estos rasgos míos de carácter que son en buena parte, como suele suceder, involuntarios, puede que heredados. Pero lo cierto es que siempre me ha parecido muy sabia la reflexión de Pascal: «toda la infelicidad del hombre viene de una sola cosa: no saber quedarse tranquilo en su casa». Y quizás tampoco creo mucho en mí mismo, porque cuando me dirigen ciertos elogios tiendo a sentirme ajeno, incómodo. Eso no significa que rechace las buenas compañías ni que tenga siempre por falsas las alabanzas. Una buena conversación, una amistad como las que la fortuna me ha deparado y una apreciación seria de algunas de mis ideas me confortan tanto como a cualquiera. Por eso mismo, solo el hecho de que tantos de vosotros hayáis dejado de hacer vuestras cosas — sin duda más interesantes — para reuniros con nosotros ${ }^{1}$ y hayáis dedicado vuestra inteligencia y vuestro tiempo a escribir unas líneas sobre nuestras ideas, es algo que me emociona y me deja perplejo. He leído además vuestras observaciones y me han parecido serias, nada gratuitas ni complacientes, con calor de amistad pero dignas también de un buen debate académico. No me parece que haya en ellas nada de mera cortesía. Seguramente no va a ser posible entrar en cada una de ellas con la minuciosidad que merecen pero quiero trasladaros a todos y cada uno por escrito y en voz bien alta, porque las emociones más personales y profundas las expreso mejor en público, mi gratitud y mi reconocimiento. De todas las cosas que uno puede llevarse a casa cuando le toca jubilarse, un puñado de amigos que hayan decidido hacer eso, es sin duda la mejor.

Por la proximidad misma, y claro, por la intensidad, me va a ser todavía más difícil hablar de mis colegas de todos los días en la Facultad, los que han urdido todo esto con esa naturalidad e inteligencia con la que en ese microcosmos de pensamiento y amistad que ha sido y es nuestra área se hacen las cosas. A la cabeza de ellos figura ahora Alfonso RuIz MigueL, una de esas inteligencias sustanciales y limpias

1 Estas palabras las pronuncié el 25 de noviembre de 2016, en el seminario que tuvo lugar en la Facultad de Derecho de la Universidad Autónoma de Madrid con colegas de muchas universidades. El «nosotros» no es aquí de los llamados «mayestáticos». Simplemente me refiero en plural a Liborio HIERRO y a mí mismo, los dos homenajeados. 
que hacen de un paraje universitario un espacio de convivencia y mejora. Y que por si eso fuera poco ha habido también circunstancias mías más personales desde hace un montón de años. Pues bien, él, ellos y ellas, nosotros, lo que unos junto a otros hemos pergeñado en ese espacio, lo conocéis bastante bien todos. Y creo que sabéis valorarlo. No voy a perder el tiempo en llamar la atención sobre la cantidad de talento que ha tenido la oportunidad de salir a la luz en ese entorno de pensamiento y amistad. Y las causas que se han defendido y se defienden en él (pienso ahora, por ejemplo, en lo que ha significado y significa el compromiso de nuestras compañeras). Pero lo que me parece quizás más importante decir y agradecer es que esa comunidad nuestra de donde brota la idea de este pequeño homenaje ha sido también un lugar en el que no se han producido desencuentros, tensiones y rivalidades de esas tan habituales entre académicos y que tanto polucionan la vida universitaria. Discusiones y debates, incluso fuertes, muchos. Pero esos antagonismos insanos, nunca. Por suerte, porque al fin y a la postre resultan ser siempre perfectamente estériles. Y eso ha sido así, quizás, porque la fortuna nos ha dotado a todos de un talante poco engreído y más cooperativo, y también, y esto ayuda mucho a explicarlo, porque a Elías DíAZ no se le ha ocurrido nunca montar una «escuela», ni generar «discípulos», ni ninguna de esas usanzas universitarias pueriles que tanto dificultan las relaciones naturales entre las gentes. En realidad uno podría decir que ni siquiera ha tenido que hacer un esfuerzo deliberado para seleccionar a la gente, porque la gente ha acudido — hemos acudido- a él espontáneamente, como guiados por una ejemplaridad tanto de pensamiento como de conducta que nos llamaba con naturalidad. Y mira tú por donde, sin proponérselo, como por una suerte de efecto difuso y paradójico, ha terminado por juntarse a su alrededor y más allá de él una cosa que no es una escuela pero es seguramente algo más profundo que eso, y una serie de colegas que dicen ser sus discípulos aunque no lo son, pero tienen con él una relación más honda y de más respeto que esa. En unas cuantas universidades, y no solo en esta, andan no pocos que se sienten inmersos en esa relación. Y hay que explicarlo seguramente por una cosa más que los que hemos vivido aquí no podemos olvidar: Elías es alguien que ha practicado de una manera natural la tolerancia. Eso sí, como él diría, la tolerancia «no acrítica». Y como ya sabemos por la lógica que una doble negación resulta ser una afirmación, lo que ha practicado ha sido la tolerancia crítica. Esas dos cosas que suenan a oxímoron, tolerancia y crítica, son difíciles de engarzar con la facilidad con la que él lo ha hecho siempre. Lo de la «crítica» es algo que entenderán fácilmente todos los que le conozcan. Pero lo de la tolerancia es algo de lo que se parlotea mucho, y se escribe mucho, pero no se practica tanto. En la vida académica tampoco, y por eso surgen muchas veces esas rencillas inoperantes que todo lo enturbian. Entre nosotros esa tolerancia es un ingrediente cotidiano, y también lo es naturalmente nuestra amistad, y también, por supuesto, la incesante crítica de todo. Y eso, a buen seguro, es lo que ha determinado que Alfonso y el resto de los compañeros se hayan propuesto estimular una reunión como esta: una actividad académica para cuestionar nuestros puntos de vista, no para hacer carantoñas insignificantes; una reunión en la que la amistad no está reñida con la crítica y, por supuesto, tampoco con la tolerancia. Muchas gracias a todos por ello. 


\section{SOBRE LIBORIO HIERRO}

Permitidme ahora también a mí que para empezar me pase a aquel lado del evento, no para hablar de mí mismo, naturalmente, sino para ejercer también mi derecho a rendir homenaje y mostrar mi admiración hacia Liborio. El título que puedo esgrimir para ello es que seguramente soy el que más tiempo hace que le conoce y disfruta de su amistad e inteligencia. De hecho yo estudié con él la carrera, me incorporé con él al departamento de RUIZ-GIMÉNEZ, y tras algunos años y algunas vicisitudes, nos vino Dios a ver a ambos en la forma de una contratación de Elías en esta Universidad Autónoma; estoy hablando de los primeros setenta del siglo pasado. Pues bien, han pasado más de cuarenta años en tareas y vivencias de lo más variopinto, y en esas estábamos cuando nos ha llegado a ambos también al unísono el tiempo de la jubilación. No soy nada aficionado al elogio desmedido ni a la hipérbole; me siento incómodo con ambas cosas. Pero creo poder decir que quienes hemos gozado de la amistad de Curro (como le hemos llamado siempre) y de su presencia entre nosotros, hemos mejorado con ello en casi todos los aspectos, excepción hecha de lo que concierne a sus elementales preferencias gastronómicas (aunque esto haya tratado de ser mantenido en secreto, todo el mundo sabe ya que la única vez que almorzó en el exquisito Zalacaín, pidió, ante la incredulidad casi ofendida del maitre, un par de huevos fritos con patatas). Por supuesto, todos hemos aprendido mucho de él en cuestiones teóricas, de las que ahora hablaré, pero también nos ha aportado muchas otras cosas más. Como maestro en actitudes y juicios en tantas y tantas circunstancias, Liborio ha sido una pieza clave en nuestras decisiones y en las de nuestro departamento (o área). Por lo que a mí respecta, entre otras cosas, y él lo sabe, no doy nunca por definitivo un juicio sobre un problema jurídico hasta que no escucho su opinión. No quiero exagerar porque está fuera de lugar, pero creo sinceramente que es una de las personas con una formación jurídica más sólida y penetrante que conozco. De esas que dibujan un jurista completo, hecho desde la teoría pero también vertido en la práctica. Tengo que decir, además, y todo el mundo lo reconoce así, que ha sido y es un profesor extraordinario. La vertiente docente de nuestra profesión, que a mi juicio es tan importante como la otra, ha sido desempeñada por él siempre en términos de excelencia. Con mucho rigor además en el contenido de lo que enseñaba. Yo he leído cartas y opiniones de alumnos suyos de esas que quizás sonrojen a quien las recibe, pero producen mucha envidia en quien las conoce. $\mathrm{Me}$ parece que su dedicación todos estos años al curso de teoría del derecho merecería, como lo ha hecho con su curso de derechos humanos, un libro final, que seguro que no me equivoco si pronostico que será un hito en la materia. Y esta misma sensación ha producido en esta su Facultad su modo de abordar los problemas de la gestión, al nivel más cercano de los cientos de problemas que se plantean hoy a las áreas, como también en responsabilidades más altas, por ejemplo como decano. Todo el mundo le ha tenido siempre y le tiene como un ejemplo de inteligencia y de saber hacer.

En cuanto a sus aportaciones académicas no necesito deciros nada. En primer lugar, naturalmente, su introducción entre nosotros del realismo escandinavo. En la filosofía del derecho española era prácticamente desconocido. Salvo algunos pocos internacionalistas (pienso en Antonio TRUYOL, por ejemplo), en España empezó a llegar a través de las traducciones de los colegas argentinos en los años sesenta. Pues bien, creo que su tesis doctoral lo puso sobre la mesa de las discusiones. Y con cierta 
actitud de distancia por su parte. Por ejemplo, la idea, que sugirió el propio Ross, de que su noción del derecho válido como algo experimentado y sentido como vinculante equivalía a lo que HART llamó los internal statements, seguida fielmente en Italia por PATTARO y por Silvana CASTIGLIONE, fue puesta en cuestión por él, y eso acabó llegando a oídos de HART mismo. Ahora diré cómo. El caso es que en la reedición de 1983 de su artículo sobre el realismo escandinavo, HART introduce en un postscript una nota en la que dice que para valorar aquella afirmación de Ross hay que leer a HIERRO, y cita minuciosamente todas las páginas correspondientes de su libro (para el lector curioso, está en la p. 169 de la edición canónica de los Essays). ¿Cómo lo supo HART? Aunque el bueno de Fernando Torres era un editor bravo y sagaz, nadie puede pensar que sus libros circularan por Oxford. Lo que sucedió fue lo siguiente: lo reconstruyo como testigo presencial. Cuando HART vino en 1979 a esta Universidad y a la Complutense a dar sendas conferencias, tuvo el gesto académico de pronunciarlas en español. Esas cosas eran muy propias de él. Ahora veremos otra. La que dictó aquí, «el nuevo desafío al positivismo jurídico», ha permanecido en español hasta hace bien poco, y la versión inglesa que se ha publicado no es de la mano del propio HART. El caso es que HART quiso reunirse la tarde anterior con los que habíamos hecho la traducción para fijar algunos temas que no veía claros. Y allí nos fuimos al Palace. Estuvimos toda la tarde, y a lo largo de ella, Curro le planteó estos y otros temas, le habló de su tesis y además le suscitó de pasada otro que tenía relación con ellos. Le dijo, por ejemplo, que a él no le parecían tan diferentes la idea del punto de vista interno/externo y la distinción entre el uso y la mención de los términos del lenguaje. Pues bien, el caso es que a la mañana siguiente pronunciaba HART su conferencia en la Complutense. Recordaréis todos lo aficionado que era Gregorio PECES-BARBA a las ceremonias. Llevado por esa afición había dispuesto una suerte de procesión de doctores desde el Decanato, que está en el ala izquierda del edificio de la Facultad, al salón de grados, que está en el ala derecha. Pues bien, en medio de esa procesión, HART nos vio fuera del cortejo y creo recordar que ni corto ni perezoso se salió de él y nos vino a explicar por qué no teníamos razón en eso del uso y la mención. Una anécdota curiosa, muy reveladora de lo que era HART, que quizás también explique por qué se quedó con las observaciones de aquel joven profesor sobre su obra.

Después está su contribución a la teoría de los derechos humanos. Como acaba de salir un libro en el que se asume casi todo su pensamiento, es fácil suponer que eso estaba ahí ya. Pero la teoría del derecho subjetivo y la discusión sobre las teorías de la voluntad o del interés no eran demasiado conocidas entre los filósofos del derecho, y sobre todo, no sabíamos calibrar la importancia que eso tenía para los derechos humanos. En el universo del derecho privado no parecía tan importante apuntarse a la teoría de la voluntad o a la teoría del interés en su versión alemana; era o parecía ser una mera pugna por una mejor conceptualización dogmática. Pero cuando nos trasladamos a los derechos humanos, esa discusión es crucial. Sin tenerla en cuenta, los niños, por ejemplo, parecen no poder tener derechos humanos. Y eso lo advirtió Curro con toda claridad. De ahí viene, me parece, su insistencia en la idea de necesidades humanas. Además, esa estrategia de argumentar los derechos poniéndolos ante un test difícil —el de los derechos de los niños en su caso- se ha mostrado siempre muy eficaz para su conceptualización; entre nuestros colegas del área, por ejemplo, ha sido muy fructífera: Pablo DE LORA lo ha hecho con respecto a los derechos de los animales, Luis RODRÍ- 
GUEZ ABASCAL respecto a los derechos de los sujetos colectivos, etc. Pero gran parte de lo que después hemos hecho todos sale de esos primeros ensayos de Curro.

Hay más libros, como todos sabéis (sobre el Estado de Derecho o sobre la eficacia de las normas, por ejemplo) y también algunos artículos extensos a los que siempre vale la pena volver, pero voy a mencionar por último — dado el poco espacio que yo tengo también en mi papel especial de homenajeador - un libro un poco más pequeño por el tamaño, pero no por cierto por la sustancia: me refiero al titulado Justicia, igualdad y eficiencia, en el que Liborio se enfrenta con el análisis económico del derecho y le pone los puntos sobre las íes precisamente para alejar cualquier pretensión de limitar el alcance de las exigencias de la justicia en virtud de ciertas consideraciones de eficiencia. La eficiencia tiene que entrar en la fórmula, no puede ser excluida despectivamente como lo hace DwORKIN, pero tiene que hacerlo con un orden y unas dosis determinadas. Pero la razón por la que lo traigo aquí no es esa, sino otra: que el libro es muy ilustrativo de la manera inteligente, sagaz y rigurosa que tiene Curro de desentrañar los problemas y argumentar las cuestiones. Una inteligencia y sagacidad que ha enriquecido cotidianamente nuestra vida en la Universidad. Solo por eso ya hubiera sido para todos un regalo tenerlo entre nosotros en el área. Luego queda, claro, todo lo demás.

\section{OBSERVACIONES Y RESPUESTAS}

Como he dicho antes, las intervenciones y breves ensayos que los colegas nos dedicaron en el seminario y todas las que aparecen en este número de la revista no son sin embargo textos indulgentes para rendir un homenaje meramente cortés y cubrir al destinatario con halagos de ocasión. No pocos de ellos, por el contrario, dejan medio maltrechas las ideas de que se ocupan, y cuando hacen preguntas siempre abren un espacio serio para la duda. Solo por eso es un auténtico desafío y un deber académico entrar a discutirlas. Bien entendido que no se trata aquí de prolongar indefinidamente los temas que suscitan, muy interesantes muchas veces, ni mucho menos de perseguir exhaustivamente cuestiones muy complejas, sino más bien de mostrar en un diálogo abierto y amistoso algunas incitaciones que me parece que vale la pena resaltar. Uno de nuestros deberes cívicos es también el de seguir dando ejemplo de diálogo como comunidad académica. En lo que a mí respecta, y a diferencia del método sistemático preferido por Liborio, más inteligente, voy a tratar de responder uno a uno a nuestros interlocutores, al menos hasta un cierto punto.

Después de la cálida y rigurosa presentación que hace de nosotros Alfonso RuIZ Miguel, de alguno de cuyos puntos me tendré que ocupar después, Manuel AtiENZA, con esa elegancia suya tan personal, circunda de palabras afectivas y fraternas las cuestiones que viene a plantearnos. Como me siento muy a gusto dentro de ese círculo de afectos y es obvio que son recíprocos, me ocuparé más pudorosamente de las cuestiones que suscita. Se refieren todas ellas a mi posición (a nuestra posición) sobre los derechos, aunque al final haya una pequeña coda interesante, y difícil, que trataré de responder. Es un placer tomar este texto como punto de partida para otros comentarios que haré después. Lo que dice sobre mi vieja posición acerca de la naturaleza de los derechos humanos es muy correcto. Pero me voy a detener, para empezar, en un 
punto. $\mathrm{Y}$ es que algunos compañeros (incluido, creo, el propio Liborio HiERRO) se han mostrado a lo largo de estos años, y se muestran ahora, un tanto reticentes con la sugerencia de mi trabajo sobre el inconveniente de aumentar sin control teórico alguno la nómina de los derechos manteniendo al mismo tiempo su pretendida fuerza como exigencias morales. Esto, que se ha llamado — no sé si con propiedad-inflación de los derechos, me parece algo que ha de tenerse en cuenta. Y se produce tanto en el discurso moral como en el discurso jurídico, sobre todo en el constitucional. Todo aquel que tiene una demanda que hacer la reviste con el ropaje de los derechos. Y si los derechos tienen tanta fuerza y hay tantos reconocidos como intereses hay insatisfechos, entonces el panorama, me parece a mí, se complica bastante. Pero mi alarma no se debe confundir apresuradamente con una invitación a una suerte de poda de derechos que hubiera que acometer quitando unos cuantos de las concepciones morales, las declaraciones y las constituciones, sino como una ordenación diferente y más estricta de su naturaleza, su justificación y su fuerza. Y ello por algunas razones: para empezar, porque el aumento del número incrementará seriamente los conflictos entre derechos, y los conflictos entre derechos, inevitables como son, no es bueno que se multipliquen. Han mostrado ya ser lo suficientemente tercos como para que no los alentemos. Tanto en el espacio de la moral, con sus dilemas y elecciones trágicas, como en el espacio más regimentado del derecho, esos conflictos son difíciles de resolver. Que haya que «ponerlos en una balanza», «ponderarlos», «sopesarlos» y todas esas metáforas al uso indica ciertamente algo que es verdadero: que los derechos entran en conflicto y hay que resolver ese conflicto; pero también puede inducir al engaño de suponer que, como las balanzas y los pesos de verdad, tenemos también nosotros un fiel y unas medidas estándar para realizar esas operaciones. Esto me parece más difícil de aceptar. Como tantas otras veces sucede, no se trata de que los derechos tengan uno u otro peso o fuerza y nosotros la vayamos a descubrir mediante una operación formalizada; las cosas suceden al revés: somos más bien nosotros los que en nuestras concepciones tanto de la moralidad como de la estructura del orden jurídico, les atribuimos un lugar y ciertas prioridades entre las exigencias morales o jurídicas. Y para eso hemos de construir en ambos mundos (el moral y el jurídico) una concepción compleja y rica de tipos de normas, estadios, bienes y fines, razones, argumentos, etc. Una visión moral, por ejemplo, es algo extremadamente complejo, que involucra principios, derechos, ideales, preceptos, instituciones, etc., y apela no solo a nuestro razonamiento, sino también a nuestros sentimientos y nuestra visión del mundo. Después de RAWLS ya no hay que insistir en ello. Y como juristas, por otro lado, somos perfectamente conscientes de la diversidad normativa, las jerarquías, las antinomias y los procedimientos que habitan en un orden jurídico moderno. Una construcción nueva, no lineal, de ambas cosas, tendría que ofrecer una solución a ese problema de la proliferación desordenada de demandas en forma de derechos. Y más ahora, cuando tras las expectativas que se han creado irreflexivamente, vienen las consiguientes frustraciones y lamentos. En el mundo de la política eso ha desembocado en una palabra mágica: «blindar». Ahora se van a blindar todos esos derechos que nuestras deficitarias y tramposas democracias han traicionado. Mal cariz va a tomar la cosa. Pero no prosigamos por ahí.

Mi vieja posición sobre los derechos humanos (que, por cierto, no tendría mayor inconveniente en corregir si hubiera razones para ello) partía de dos decisiones teóricas deliberadas: 1 . Los derechos humanos son derechos morales, y por tanto, para dar 
cuenta de ellos y de su justificación hay que introducirse en el universo de la ética y elaborar una concepción compleja que les asigne un lugar dentro de ella. 2. Los derechos humanos se van ampliando, efectivamente, pero no sin control, sino de una forma que se puede aludir con la expresión de SINGER del «círculo en expansión». Ellos mismos son un producto de la expansión de la razón moral hacia la universalidad, y cada uno de ellos tiende también a su vez a expandirse para proteger esferas nuevas de la peripecia de los seres humanos. Como consecuencia de ello, más que como enunciados aislados y rotundos, se pueden concebir como conjuntos y subconjuntos de derechos («racimos», ha dicho alguien) en los que cada derecho ocupa su lugar en el espacio moral - pertenece a un racimo - y en la jerarquía interna de cada conjunto. Esta es la complejidad del asunto. Y en ese mundo complejo, me parece, podremos introducir algo de orden y jerarquía para evitar el efecto perverso de la mezcla de la fuerza y la proliferación, pero no voy hacerlo aquí, por razones obvias.

Con su habitual sagacidad Manuel ATIENZA detecta que la presentación de los derechos de Liborio HIERRO está más cerca del derecho, mientras que la mía tiende a moverse en el mundo del discurso moral. Liborio es más (y mejor) jurista que yo, y me parece que su preocupación es más la de dar cuenta de los derechos en un momento cercano al aterrizaje (por así decirlo) en el derecho positivo (aunque no todavía como meros derechos constitucionales o legales, como es tan habitual); la mía en cambio quiso en su momento subrayar más su naturaleza moral. Hay que recordar que la teoría de los derechos humanos no estaba entonces nada desarrollada entre nosotros. Se podían contemplar, y admirar, ejemplos de apuestas muy firmes en su favor, pero sin gran acompañamiento teórico. Se movían en el marco de un activismo político muy explícito y un positivismo jurídico un tanto tradicional, y estaban lastradas además por la obcecación lingüística de suponer que no podían ser llamados derechos más que los derechos creados por el legislador positivo (nacional, constitucional o internacional). $\mathrm{Y}$ eso, creo, abortaba radicalmente su vuelo moral imprescindible. Pero no nos entretengamos en esto. Vayamos a la coda. Hasta ahí, me parece, Manuel ATIENZA está de acuerdo conmigo, pero lo que hace es tomar esta opción mía como punto de partida para introducirme - para introducirnos - en una suerte de trilema: uno no puede aceptar simultáneamente - sugiere- la configuración de los derechos humanos en términos morales, la realidad de que los derechos humanos juegan un papel central en nuestros ordenamientos, y la posición del positivismo jurídico. Se supone que si uno acepta una de estas tres cosas tiene que rechazar al menos alguna de las otras dos. Y como creo que él acepta conmigo, con nosotros, los dos primeros cuernos del trilema, piensa que la única conclusión que cabe es abandonar el positivismo jurídico como una posición imposible. Pues bien, yo creo en efecto que los derechos humanos pertenecen originariamente al discurso moral y es en él dónde hay que ir a examinar su naturaleza básica; y creo también que, una vez constitucionalizados y protegidos jurídicamente, juegan un papel decisivo en la dinámica de nuestros ordenamientos. Pero ¿por qué es imposible pensar entonces que para identificar como jurídica una decisión, una norma o una institución —o si se quiere a la mismísima constitución - baste con acudir a un conjunto de criterios de procedimiento y de contenido que no tienen una relación necesaria con la moral? Podemos hacerlo, y de hecho lo hacemos cotidianamente para saber qué es el derecho de nuestro país. Porque aceptar la primaria naturaleza moral de los derechos básicos y su papel fundamental en los órdenes constitucionales actua- 
les no es postular una conexión definicional o lógica entre la moral y el derecho, sino simplemente llamar la atención sobre el hecho contingente de que en nuestro contexto histórico ciertas convicciones morales han influido decisivamente en el derecho. Tanto que si uno quiere interpretar y aplicar las normas jurídicas (o al menos algunas de ellas) tiene que utilizar el razonamiento moral para obtener sus conclusiones. No nos engañemos, si uno quiere discutir una sentencia del Tribunal Constitucional en un recurso de amparo puede - y seguramente debe- acudir a premisas morales para argumentar, pero antes tiene que saber que eso - tan largo y farragoso- es en efecto un recurso de amparo y una sentencia del Tribunal Constitucional, y no una mera propuesta moral o una ocurrencia extralegal. Es decir, que es uno de los elementos que componen esa práctica social convencional que llamamos derecho y que identificamos como jurídicos utilizando un conjunto complejo de criterios entre los que no hay necesariamente ninguna exigencia moral. Y me parece que el positivismo jurídico, a lo largo de su diversa y heterogénea historia, se había propuesto centralmente como misión establecer esos criterios para que sepamos que eso es un fallo del Constitucional, una ley del Parlamento, un precedente judicial, un contrato o un precepto constitucional, etc. Y creo que ha cumplido bastante satisfactoriamente con esa misión. Saber esas cosas puede parecer hoy en día irrelevante, pero irrelevante no equivale a erróneo o equivocado. Yo creo, por otra parte, que no es tan irrelevante. Así que sigo pensando que no se me han dado argumentos suficientes para abandonar el marco del positivismo en ese sentido lato. Tengo que decir además, ya más en tono de humor, que la recompensa que se me ofrece por abandonar esa tradición me parece poco sustanciosa: apuntarme al «postpositivismo». No me veo como «post»-nada. Quien «deja atrás» algo tiene que saber con alguna precisión a dónde se propone viajar, y debería tener una hoja de ruta razonablemente clara. No sea que le vaya a pasar como a los postmodernos, que solo son «post» respecto a lo moderno, pero no saben del todo a dónde van, si de vuelta a lo premoderno o camino del puro arbitrismo, o ambas cosas a la vez. Este, desde luego, no es el caso de Manuel ATIENZA, porque harto nos tiene dicho ya dónde está y qué visión tiene del derecho, pero con todo no acaba de convencerme. Ahora seguiré hablando de ello, con uno de sus textos en la mano.

En el sustancioso comentario que nos ha enviado Ángeles RóDENAS se parte de una posición que me complace mucho. Cuando en 2001 oí a Juan RuIZ MANERO en Imperia exponer el texto que escribió con Manolo sobre la dimensión institucional del derecho y la justificación jurídica me pareció, y así se lo dije a Juan, una novedad importante en sus planteamientos teóricos. Reconocían en él que en su obra anterior habían obviado esa dimensión institucional o no la habían tenido suficientemente en cuenta. Y eso me pareció un gesto ejemplar de honestidad intelectual. Pero también me pareció entonces, y me ha parecido ahora al releerlo, que lo enfocaban centralmente hacia el tema, que habían tratado tanto, de la justificación jurídica, de los conflictos entre normas en el derecho y de su idea de la prevalencia de los principios en sentido estricto. Luego volveré sobre esto de los conflictos y la prevalencia, porque es precisamente el tema que suscita Ángeles. Lo que me interesa ahora es subrayar que al hacerlo ambos confesaban que tenían que añadir a su esquema de Las piezas del derecho una nueva categoría de normas, las normas institucionales. Pues bien, a la hora de presentar este carácter institucional del derecho, lo hacían ofreciendo los varios aspectos que esa expresión pudiera tener, y que, me parece, aceptaban en su totalidad como rasgos 
propios del sistema jurídico. Los transmito telegráficamente: El derecho es un conjunto de hechos sociales cuya existencia y persistencia depende de la aceptación colectiva de ciertas reglas constitutivas; es un conjunto de normas practicadas en una sociedad, en el sentido de que ciertos órganos disponen del monopolio de resolver las disputas usando esas normas y la población actúa en correspondencia con ellas; es un conjunto de normas que regla los procedimientos de resolución de disputas con un procedimiento, unos límites y unas autoridades; es un sistema que regula su propia creación y aplicación; es un sistema que ofrece un criterio de reconocimiento de sus normas basado en la aceptación de un sistema de fuentes y autoridades; y, para terminar, es un sistema en el marco del cual operan las demás instituciones sociales. En Las piezas del derecho - confesaban los dos autores- no tuvimos presentes las muy diversas exigencias regulativas que surgen de la dimensión institucional del derecho ${ }^{2}$. Y yo me dije a mí mismo ¿no habrán, entonces, obviado precisamente lo más importante? ¿No es esto que según confesión propia no tuvieron presente el núcleo de lo que consideramos un sistema jurídico? Y, por fin, ¿no es esto una buena presentación de lo que los positivistas actuales dicen que es el derecho? A mí se me antoja que sí, y no me parece que cometamos ningún pecado de lesa teoría si pensamos que para dar cuenta de lo que el derecho como práctica social es, primemos esas dimensiones institucionales, que no son sino las conclusiones del positivismo. Y cuando algún viajero nos pregunte cómo puede conocer, por ejemplo, el derecho del Sultanato de Omán, que es una monarquía absoluta, con un parlamento demediado, escasos derechos constitucionales y mucha influencia religiosa, le podamos decir que busquen esos rasgos institucionales que ahí se describen y lo hallará. Es decir, que cuando esos rasgos se dan estamos en presencia de un orden jurídico. Y algunos de esos órdenes, entre ellos, para fortuna nuestra, el español, han dado en organizar esos rasgos institucionales de acuerdo con algunas exigencias ético-políticas que incluyen la incorporación de tablas de derechos a los que dan una gran fuerza jerárquica, la separación entre la iglesia y el estado, y el ideal del imperio de la ley como modo de controlar el poder. Pero no me parece que se gane gran cosa diciendo que solo estos órdenes tan afortunados son derecho en sentido estricto, y los otros todavía no, o nunca lo han sido. No encuentro aceptable una teoría con la que se pueda afirmar, por ejemplo, que el derecho romano no era todavía derecho. Así que yo, por mi parte, si fuera el caso, más que abandonar el positivismo así entendido, lo que haría con toda prisa es abandonar el Sultanato de Omán y venirme para acá a discutir con los amigos sin que nadie nos persiga por criticar los caprichos del califa.

Y en relación con esa suerte de amistoso cerco que nuestros colegas de la Universidad de Alicante nos vienen haciendo para que ingresemos en la orden de los postpositivistas, viene ahora a cuento hablar de las dos densas intervenciones que hacen Josep Aguiló y Jesús VEGA. He dicho densas, no espesas. Esta distinción es pertinente muchas veces, y la hago ahora para pedir de antemano disculpas por no descender en mis breves observaciones al detalle que merecen. Son también ambas, como lo han sido otras con la misma pretensión, tratamientos mediante lo que se ha llamado tra-

2 No estoy entrecomillando para no dar a esto un aspecto excesivamente formal, pero creo no haber traicionado las ideas que transmitían en ese texto, que releo ahora en Para una teoría postpositivista del Derecho, 9 y ss. 
dicionalmente el lecho de Procusto. Afortunadamente se trata de la variante amable del tratamiento. Procusto gustaba de amputar las partes del cuerpo que se salían del lecho (la variante cruel del tratamiento), pero también de estirar los miembros que no alcanzaban para hacerlos coincidir con él. Creo que Pep y Jesús tienen la intención sobre todo de hacer algunos estiramientos en nuestros contraídos músculos positivistas.

Josep AguiLó, que ve perfectamente los diferentes planos en los que se mueve mi propuesta del imperio de la ley, afirma detectar en ella una ambigüedad, y me invita a que me pronuncie al respecto. En primer lugar sobre la ponderación. Y aquí he de anotar una cierta perplejidad respecto del postpositivismo. Afirma Pep que los positivistas nos aferramos a las reglas como entidades puramente semánticas, mientras que ellos «presuponen que toda regla expresa ya una ponderación de principios (y/o derechos)» Si esto es una afirmación empírica es dudosa, y si es una afirmación normativa es, me parece, un tanto excesiva. Pero lo que me preocupa de ella es que introduce excesivamente en todo el proceso aplicatorio la ponderación. Si la regla es producto de una ponderación hecha ya por el legislador ¿por qué hacer otra por el juez? ¿No parecería más correcto aplicar ya subsuntivamente esa regla ponderada? ¿Y en qué consiste la segunda ponderación? Dejo ahí esas preguntas para debatirlas en otro momento y con más espacio.

Luego suscita la cuestión de la respuesta correcta. Siempre me he sentido más inclinado hacia la negación de la única respuesta correcta. Y no me parece que eso nos obligue a abandonar la distinción casos fáciles/casos difíciles y sustituirla por la distinción casos regulados/no regulados. Puede haber casos regulados difíciles por muchas razones normativas y no normativas. Y los casos difíciles (regulados o no regulados) han de ser abordados apelando a otros ingredientes del orden jurídico, incluidos los principios, pero no solo ellos (también pueden contar los usos sociales, el precedente judicial, etc.). La segunda implicación de la negación de la respuesta correcta es — dice Pep-que no puede generarse en torno a ella una «genuina deliberación». Aceptando su taxonomía de las deliberaciones, no veo por qué no puede darse un «debate cooperativo y temático» para decidir un caso no regulado. Puede haber muchas razones (prudenciales, por ejemplo) para que un caso se decida en un sentido o en otro, y sobre ellas se puede debatir sin ánimo conflictivo. Me atrevería a decir que, de hecho, sucede así con frecuencia en las salas de los tribunales. Para finalizar, lo que me parece que no calibra demasiado bien el postpositivista o neoconstitucionalista que abrace la tesis de la única respuesta correcta es el grado de objetivismo o cognitivismo moral al que se compromete. Confieso que me inclino más hacia el no cognitivismo en materia moral, pero con muchas dudas. Me gustaría acercarme más a la posición que afirma la objetividad en materia de juicios de valor, pero, como digo, con dudas, miedos y grandes temblores. En todo caso, yo me lo pensaría mucho antes de construir una teoría del derecho que dependa demasiado de un compromiso moral tan fuerte. Pero esto es mucho grano para este breve molino. Comprenderá Pep que no lo pueda moler en tan pocas palabras.

Y vamos con Jesús VEGA, que, todo hay que decirlo, aunque su texto es también denso en el buen sentido de la palabra, me parece que no ve con igual claridad los planos distintos en que se mueve mi propuesta. Que viene a secuenciarse así: un valor moral sustantivo (la autonomía), que, por razones de variada naturaleza exige un 
conjunto de atributos formales de las reglas, que deben ser respetadas por el poder e interpretadas con lealtad semántica. Es decir, una teoría moral del imperio de la ley. Y creo que Jesús la ve como una teoría formal del derecho, que, obviamente, es imposible si se pretende incluir en ella algún valor moral sustantivo. Que una teoría moral no sea sino una parte, un capítulo, de una teoría completa de la Justicia es algo muy común en la reflexión ética contemporánea. Incluso la teoría de RAWLS se declara así. De forma que esa «ambigüedad metateórica» que se dice que padezco no la veo tan clara, a no ser, obviamente, que me haya equivocado en algún momento. Y ello porque no trato de presentar una teoría del derecho, ni libre de valoraciones ni presa de valoraciones, es decir, mi imperio de la ley no es una teoría del derecho, sino una teoría moral sobre cómo debe ser el derecho para empezar a ser justo. No sé si aventurar una hipótesis general sobre el postpositivismo y el neoconstitucionalismo: a veces pienso que han asimilado de tal modo la realidad del derecho con la realidad del derecho en los estados constitucionales que han olvidado la distinción entre derecho y derecho justo. Espero que esto no le haya pasado al bueno de Jesús VEGA.

Aunque esto pueda estar un poco desordenado, aquí puede situarse también la respuesta a Miguel Ángel RoDILLA, que, aunque quizás no en los mismos términos, también nos interroga sobre la procedencia de declararse todavía hoy positivista. Corresponde dar esa respuesta más a Liborio HIERRO, que es a quién Miguel Ángel interpela más directamente. Estoy seguro de que será para mí fácil, como lo ha sido siempre, identificarme con sus argumentos. Pero quiero hacer un par de puntualizaciones, no guiado solo por la cortesía, sino por el afecto y el respeto que tengo desde hace mucho tiempo a Miguel Ángel y a sus trabajos. Una primera puntualización sería esta: Yo no sé si no está identificando demasiado deprisa el positivismo jurídico con lo que CAMPBELL llama la teoría jurídica del positivismo ético, que yo comparto bastante (aunque con muchas precauciones, empezando por la de su nombre mismo y la de su posible confusión con el llamado por BOBBIO «positivismo ideológico»). Por lo que a mí respecta son dos cosas diferentes. Cuando yo quiero identificar un sistema jurídico, me remito a esa lista de aspectos institucionales que mencionaban antes ATIENZA y RUIZ MANERO, y eso me basta. No es que con esto se informe uno de muchas cosas, ni haga yo ningún gesto triunfal y «me declare» positivista, como si se tratara de posicionarme entusiásticamente en alguna gran contienda. Simplemente me parece que esos rasgos son suficientes para contestar a una pregunta que solemos hacernos los juristas sobre el derecho de una comunidad ajena o el nuestro propio. Y esos rasgos identificatorios tendrían que valer para captar las propiedades de todas esas prácticas que llamamos comúnmente derecho, algo que los comparatistas, por ejemplo, intentan al hacer sus manuales: comparar unos con otros los diferentes derechos, los diferentes sistemas jurídicos así identificados. Si no tuviéramos un criterio común para saber qué es el derecho, no cabría el derecho comparado porque no se sabría nunca si estábamos comparando cosas de la misma naturaleza. Me parece que ese criterio lo ha suministrado hasta ahora el positivismo. Y después viene lo otro: sobre ese cuerpo de prácticas proyectamos una exigencia moral: el imperio de la ley y lo que ello lleva consigo, y entonces es cuando estamos en el llamado por CAMPBELL, de manera confundente, «positivismo ético». Y esto ya es harina de otro costal, porque lleva consigo, efectivamente, un conjunto nada pequeño de opciones morales que se pueden compartir o no, pero que no son definitorias del derecho. $\mathrm{Y}$ viene esto a cuento de la segunda puntua- 
lización. Me parece que para mantener los ideales de la Ilustración es más adecuado esto segundo, la ética del legalismo, que lo anterior, el positivismo como acercamiento al derecho. Seguramente esto también, en un sentido: entre los ideales de la Ilustración estaba el acercamiento científico a la realidad humana, y eso es lo que se propuso siempre el positivismo contemporáneo (desde BENTHAM). Pero mi lealtad a la Ilustración se manifiesta sobre todo en la apuesta por el imperio de la ley. Y por lo que a los efectos retóricos respecta, desde luego tiene razón Miguel Ángel cuando dice que hoy no tiene sentido esgrimir el positivismo contra el iusnaturalismo teológico de los años cincuenta. Los curas trabucaires de la posguerra han desaparecido ya, por suerte. Hoy se da todavía entre nosotros un iusnaturalismo de raíz religiosa un poco vergonzante (vergonzante en el sentido de que se suele llevar en secreto); yo simplemente no lo comparto porque me parece que no se sostienen las conclusiones morales o científicas inferidas a partir de supuestos mandatos $\mathrm{u}$ ordenaciones divinas, aunque no esgrimo nada contra él, ni - quiero creer- contra nadie. Y tampoco tengo gran interés en proclamarme nada. Ni me parece que mantener un punto de partida positivista sea incompatible con el principialismo o con el neo-constitucionalismo. Pero diría que lo mantengo con cierta desgana, sin hacer de ello un casus belli. Debe ser por la edad.

Así enfocado y enfriado el asunto me parece que puedo empezar a dialogar con Ángeles RÓDENAS. Que me disculpe por haber utilizado la base de su argumentación para responder también a ATIENZA y a RODILLA, pero era necesario también para discutir el suyo, porque quizás su planteamiento no sea sino producto del conflicto que genera olvidar el legado positivista (la dimensión institucional del derecho) en aras de una presencia demasiado acentuada del mensaje postpositivista (la primacía de los derechos como principios en sentido estricto). Lo que ella plantea no parece un problema de positivismo o postpositivismo, sino un problema de resolución de conflictos entre pautas, y es un tema que han suscitado también otros amigos y amigas: se trata de examinar mi contundente afirmación de que los derechos humanos tienen vocación de absolutos, es decir, que cuando entran en conflicto con otras exigencias morales tienden a prevalecer, y solo pueden ser sobrepasados o limitados por otros derechos. Esto yo no lo sostendría en relación con la mayoría de los derechos entendidos en sentido legal, porque, como vamos a ver, pueden aparecer restricciones, pero me pareció plausible mantenerlo respecto a los derechos humanos como derechos morales. Supongo que sobre esa convicción mía gravitaban presencias tan fuertes como la de la prioridad lexical de RAWLS y la idea de los derechos como triunfos de DwORKIN. Y me parece que puede abordarse el problema si, como lo hace Ángeles RóDENAS, diferenciamos el universo moral del universo jurídico. En el discurso moral las exigencias institucionales son más débiles y secundarias. Por ejemplo, si se mantiene como exigencia moral la libertad de expresión tiene que aceptarse que en determinadas circunstancias se establezcan turnos de palabras para la deliberación y no se permita hablar a una persona fuera de su turno. La exigencia institucional limita aquí el ejercicio omnímodo del derecho moral. También para el razonamiento moral, como ella dice, son importantes a veces las razones institucionales. Pero para el discurso jurídico son esenciales. Me atrevería a ir más lejos: son el núcleo del derecho. Ese tejido tan tupido de reglas constitutivas, agencias de decisión, procedimientos, acciones legales formalizadas, plazos, sentencias no impugnables, etc., es el derecho mismo, y por eso cuando una argumentación que tiene por objeto los derechos fundamentales tropieza 
con una de esas barreras institucionales suele suceder que aparentemente la exigencia institucional se impone al derecho, pero esto es porque se mira el conflicto solo desde la perspectiva de la argumentación, y no se amplía la mirada hacia lo que importa, que es la condición jurídica del litigio. Con otras palabras: lo que viene a suceder no es que se le superponga arbitrariamente una exigencia institucional a un derecho fundamental, sino simplemente que se le recuerda a quien está argumentando, al litigante, que se está saliendo del campo de juego, se está saliendo del derecho, que sus razones no van a valer como razones jurídicas. Y puede resultar, en efecto, que tales dimensiones institucionales impongan al discurso jurídico de los derechos muchos tipos de barreras: institucionales, formales, comunitaristas, consecuencialistas, y hasta puramente arbitrarias. Y, claro, entonces lo que le queda a uno por hacer es sencillamente afirmar que ese orden jurídico no respeta tanto los derechos constitucionales, o los derechos humanos, o los limita arbitrariamente.

Y a propósito de esto, tengo ahora que enlazar con la ponencia de JAHEL QUERALT, que también versa sobre mi viejo artículo acerca del concepto de derechos humanos. No puedo ocuparme de todos los matices y desacuerdos que expone en su sustancioso paper, pero tengo que decir que hace una buena fotografía de lo que son los elementos fundamentales de mi pensamiento. Aunque eso sí, en el retrato incluye también algunos rasgos en los que no me reconozco tanto. Respecto de la mal llamada inflación de los derechos, parece que todo mi pensamiento estuviera armado exclusivamente para enfrentarme a esa realidad, cuando de hecho lo que yo pretendía era nada más que ofrecer una conceptualización rigurosa de los derechos humanos como derechos morales. Esto sí lo detecta, pero no parece mantenerse en ese plano, y contrasta mi teoría con la práctica jurídica de los derechos constitucionales. Para decirlo un poco sintéticamente, me critica por montar una teoría de los derechos humanos que tiene poco que ver con la práctica. Pero mi teoría es una construcción moral y la práctica a la que apela es la práctica jurídica. La pregunta entonces que me plantea, no sé si conscientemente, es la pregunta por la relación de los derechos humanos como derechos morales y los derechos humanos como derechos fundamentales o constitucionales. Y me adscribe más, aunque no del todo, a la concepción ortodoxa que sostiene la «tesis del espejo», según la cual —cito— «el actual sistema de derechos humanos legales es un intento de cristalizar en normas jurídicas los derechos morales». A mí esta tesis, en efecto, me parece que tiene un peligro: que legaliza excesivamente el discurso moral. Es menester encontrar otra manera de pasar de un universo al otro sin tener que recurrir a esta tesis especular. Creo que hay que distinguir de otra manera los principios morales de los derechos constitucionales, o para expresarlo en términos rawlsianos, tan caros a JAHEL, entre la posición originaria y el estadio constitucional o incluso el estadio legal. En la primera lo que se hace es elegir unos principios morales básicos que reflejan unos pocos derechos muy generales (por ejemplo, el derecho al máximo de libertad compatible con una igual libertad para los demás), y en el segundo o en los segundos, y con un poco más de conocimiento de las circunstancias (es decir con menos velo de ignorancia), se articulan esos principios en derechos constitucionales. También viene esto a propósito del tema ya mencionado de los derechos absolutos, aunque solo lo voy a mencionar aquí. Le recuerdo a JAHEL que en la posición originaria de RAWLS se establecen también una reglas de prioridad, y muy en particular, la regla de la prioridad 
de la libertad, que dice muy explícitamente que la libertad no puede ser limitada sino en aras de la libertad (for the sake of liberty). Si estos principios son principios para las instituciones, es decir, tienen como destinatarios a los constituyentes, entonces les están diciendo que otorguen mucha fuerza a algunos derechos constitucionales o fundamentales. Y se lo recuerdo porque eso, como he dicho antes, es seguramente la exigencia moral que sustentaba mi apuesta fuerte por la propiedad de absolutos de los derechos morales básicos. Es posible que sea preciso flexibilizar mi posición, aunque no estoy muy seguro de ello, pero también JAHEL tiene que ser precavida, no vaya a ser que la orden de los rawlsianos le retire la licencia para predicar.

Y para terminar quiero deshacer un malentendido sobre la idea de inalienabilidad. Define bien JAHEL la idea de inalienabilidad como la indisponibilidad de los derechos básicos por parte de su mismo titular, pero después pasa a poner contraejemplos no del todo convincentes. Menciona la propiedad, que yo dudo que sea un derecho básico en el sentido de defensa ante cualquier objeto de propiedad (si lo fuera cualquier expediente de expropiación sería contrario a los derechos básicos), pero también afirma que uno puede renunciar a la libertad de movimiento ingresando en un monasterio o alistándose en el ejército. Creo que en este caso no distingue entre la titularidad de un derecho y su ejercicio. Uno puede decidir no moverse ni viajar, pero no puede decidir no tener la libertad de hacerlo, como uno puede decidir votar, no votar o votar en blanco, pero no puede decidir no tener derecho al voto (venderlo o enajenarlo, por ejemplo). Es la libertad lo que es inalienable, no lo que uno hace en virtud de ella. Y esto viene a cuento también por lo que respecta a la vida, en particular a la propia vida. Porque a mí la vida no me parece un derecho tan fundamental como se afirma. Si así lo fuese sería inmoral disponer de ella (como se ha afirmado históricamente); a mí sin embargo se me antoja que, en algunas circunstancias, disponer de la propia vida no es solo, como ya sabemos, un acto propio de los héroes y de los santos (que no condenamos, sino que admiramos), sino casi hasta un deber moral. Y es ahí donde se ve que la libertad como derecho básico y general está por encima de la vida, que no es sino un objeto más de la misma, una realidad más sobre la que ejercer la propia libertad. Pero esto, obviamente, tiene que quedar para otro momento.

Hay que recordar que todo esto viene de muy atrás. Me alegro mucho de que Antonio Pérez LuÑo lo haya recordado, porque tuvo la caballerosidad de responder a mi ponencia de entonces teniendo él como tenía más y mejores títulos académicos que yo para presentar el tema exhaustivamente. Ahora me recuerda con gentileza cómo arremetí entonces contra sus sabias consideraciones sobre el peligro de que una concepción abstracta de los derechos humanos se fuera por los cerros de Úbeda. Yo tomé entonces sus invitaciones a bajar a la historia y la realidad humana como una manera errónea de proponer una fundamentación historicista. Creo recordar, en efecto, que entonces había entre nosotros quienes querían escapar del dilema entre derechos humanos desde el positivismo legalista y derechos humanos desde el derecho natural, que son, en efecto, dos caminos sin salida, recurriendo a la historia. La fundamentación de los derechos humanos habría de ser histórica, se decía. Y yo interpreté mal las recomendaciones de Antonio de bajar un poco a la tierra y a las peripecias de los hombres, y creí que era también la suya una propuesta historicista. Me alegro de tener la oportunidad de poder decirle que, leyendo ahora sus acotaciones de entonces, siento que fui 
injusto con él. Y no solo por eso, sino por algunas otras cosas que, elegantemente, no menciona. Pero hay que entender que yo, efectivamente, quería huir de la tierra y de la historia, y más que nada de la dogmática jurídica de los derechos constitucionales, para elaborar una teoría, un concepto ético, y la ética, como gusta de recordarnos Javier MugueRZA, es esencialmente contrafáctica.

Y a propósito de elaborar teorías y pensar la ética, quiero aprovechar un comentario inicial de Eusebio FERNÁNDEZ, que nos advierte que puede haber quien nos critique por dedicarnos a la teoría, de que se nos puede decir que la mejora teórica «es insuficiente, e incluso puede tener un efecto paralizador o cómplice» frente a la cruda realidad de la violación de los derechos humanos. A mí esta crítica, que efectivamente a veces se oye por ahí, me parece sencillamente estúpida y vulgar. Eusebio tiene razón, por supuesto, en que los derechos humanos tienen una dimensión práctica, pero esto le sucede por definición a todo componente de la ética. Y le agradezco que recuerde también que tanto Liborio como yo hemos hecho algo en ese mundo práctico, aunque este no sea más que un modesto caso particular del principio general de que uno tiene que hacer lo que debe. Pero la idea de que alguien pueda objetar que dedicarse al estudio de la ética supone de algún modo dar la espalda a las inmoralidades públicas cotidianas me parece que no debe ser siquiera tomada en consideración. Igual que me parece banal y pobre la idea contraria, por mucho que la haya sostenido BOBBIO en un momento de distracción, de que en punto a derechos humanos lo que hay que hacer es lanzarse a su defensa práctica sin saber lo que son ni por qué deben defenderse. Este prejuicio acrítico en favor de los derechos y su valor autoevidente es seguramente uno de los componentes de su desmedida proliferación actual. Pero doy por seguro que Eusebio no se deja contagiar por estas cosas, porque inmediatamente después de transmitirnos la advertencia se sumerge en algunos temas teóricos de cierto alcance sin que parezca darle miedo la crítica del filisteo. Y lo hace señalando además algunos en los que Liborio y yo no estamos de acuerdo. Esto es interesante, sin duda, y vale la pena hacer alguna observación sobre ello. Me interesan especialmente dos de ellos. El de la conexión derechos morales —orden jurídico—, y el de la presencia del contexto de descubrimiento en la argumentación moral de los derechos. Nos dice Eusebio que «aunque el concepto de derechos humanos pertenece a los conceptos morales, su desarrollo completo precisa de su extensión al campo político y jurídico». Pero, cabría preguntarle, ¿por qué cree él que esto es así? Nos encontramos con frecuencia con nociones que «pertenecen a los conceptos morales», como él escribe, y sin embargo no nos inclinamos a suponer que su «desarrollo completo» precise de su extensión al derecho: las virtudes, las nociones de lo moralmente bueno, las acciones benevolentes, los actos paternalistas, etc. Es más, muchas veces pensamos incluso que deben estar al margen de las normas jurídicas y de la competencia del legislador. ¿Por qué entonces esto no pasa con los derechos morales básicos? Mi respuesta, que algún día me gustaría elaborar detenidamente, es la siguiente: los derechos humanos habitan el territorio moral de la Justicia. Dentro de ese territorio se encuentran entre aquellas exigencias morales para proteger las cuales la ética misma autoriza el recurso privado a la fuerza. Pero el recurso privado a la fuerza está generalmente vedado por el orden jurídico, que es un orden cuyo sentido último es precisamente excluir el uso de la fuerza en la sociedad. Y sustituir el recurso privado a la fuerza que autoriza la ética por la coacción que organiza el derecho es lo que hace necesario transitar desde los derechos en sentido 
moral a los derechos constitucionales o legales. Perdón por la concisión en un tema de esta envergadura.

Supongo que Liborio HiERro tendrá más cosas que decir sobre el uso de la noción de necesidades humanas, que es el segundo objeto de atención de Eusebio. No sé muy bien si la vinculación de la noción de necesidades humanas con el contexto social lleva tan claramente a la cuestión de la nómina de los derechos, y dudo que sea algo que nosotros dos nos hayamos planteado ni siquiera en nuestros desacuerdos. Mucho menos, creo, apelar al contexto de descubrimiento. Por lo que a mí respecta, he de confesar que no me convence del todo la operatividad argumental del concepto de necesidades humanas. En esto, en efecto, me distancio de Liborio. Creo que la idea de necesidad lleva lógicamente consigo una dimensión teleológica que acaba por hacerla una idea insaciable: para qué se necesita la libertad religiosa, el sufragio, o la atención médica; a esto se responde enunciando un fin u objetivo (realización personal, participación política, salud, etc.) respecto del cual cabe hacerse de nuevo la pregunta por su necesidad, y a su respuesta se repregunta, y así sucesivamente. Pienso que en el fondo del discurso de las necesidades se halla siempre una concepción presupuesta del ser humano como un ideal para alcanzar el cual se dispone la cadena de necesidades y su satisfacción. Por tanto no son las necesidades las que definen cuáles han de ser los derechos, sino los rasgos que se atribuyen al modelo ideal. Esto, me parece, evita la enojosa cuestión del contexto social. Y digo enojosa porque algunos modos de abordarla acaban por despeñar a los derechos básicos por el precipicio del relativismo. Si los contextos sociales son tan variables y definen el contenido de los derechos, entonces los derechos son también variables. No se le dé más vueltas. Si en unos lugares y momentos se necesitan unas cosas y en otros, otras, en unos habrá unos derechos que no habrá en los otros. Y si seguimos la sugerencia de Eusebio FERNÁNDEZ e incluimos el llamado en filosofía de la ciencia contexto de descubrimiento, puede incrementarse el peligro. En cualquier argumentación práctica el contexto de descubrimiento puede proveernos de razones auxiliares, a veces importantes, pero nunca de razones operativas. Esas tienen otra dimensión, y ahí, a mi juicio, es donde habitan los derechos básicos. Vuelvo a pedir perdón por lo expeditivo del argumento.

Voy a responder aquí a las observaciones que me hace en su escrito Luis RoDRíGUEZ AbASCAL. Trabajar con Luis ha sido para todos, creo, uno de esos regalos inopinados que nos brinda la fortuna. Pero aquí hay que hacer frente a sus comentarios. Que lo haga ahora no tiene ninguna razón de ser especial. Podría hacerlo en otros lugares, porque Luis hace tres o cuatro observaciones que atañen a temas diversos y por eso mismo encajarían en varios momentos de este escrito. Comienza por señalar un punto en el que no puede acompañarme. Aunque con cierta cautela, yo apoyé la tesis de que había una sorprendente correlación entre el comunitarismo como filosofía moral y el nacionalismo como credo político. Dando por descontado que toda posición política (tanto en lo que atañe a la arquitectura institucional como a la práctica política) ha de tener como base de sustentación una concepción moral, me preguntaba por la base del nacionalismo, y encontraba (y encuentro) sorprendentes coincidencias epistémicas, ontológicas y axiológicas entre el comunitarismo y el nacionalismo. Me refería, naturalmente, al nacionalismo más etnicista, no al nacionalismo armado artificialmente sobre un Estado ya organizado (con himnos, lágrimas y selecciones de fútbol); a la 
idea de lo que llamaba nación-alma más que a la idea de nación-organización. Él dice que comunitarismo y nacionalismo son cosas heterogéneas y tienen un objeto distinto. Yo sigo pensando que ese nacionalismo no es más que la aplicación a la comunidad política y a la construcción de la ciudadanía de las ideas básicas que el comunitarismo ha formulado tradicionalmente. Porque el comunitarismo, o como quiera se llamara antes, está lejos de ser una teoría reciente. Esto se ve con claridad en un supuesto límite: la filosofía del tercer Reich. Esa filosofía pivota en torno a la Volksgemeinshaft y a la pertenencia a ella como identidad ciudadana que confiere la calidad de verdaderos alemanes. Es, obvio es decirlo, una filosofía antiliberal. Creo que lo que el comunitarismo contemporáneo ha hecho ha sido dar una formulación rigurosa, y también antiliberal, a ideas que ya estaban en el ambiente desde el siglo XIX, y de las que se ha alimentado el nacionalismo contemporáneo. Me parece bastante evidente, por ejemplo, que el nacionalismo confiere un estatus moral al «pueblo», que se superpone al estatus moral de los individuos que lo componen. Y a partir de ese esquema, el relato comunitarista puede funcionar con eficacia también para él. Si no, ahí están las admoniciones de MACINTYRE en favor del patriotismo. Pero esta idea no voy a poder perseguirla aquí, aunque me gustaría hacerlo.

Tiene razón Luis en que yo soy más «berliniano» que Liborio. Admiro a BERLIN, y también su famoso artículo. Creo que en general ha sido mal interpretado, quizás por alguna culpa del propio BERLIN, que pasa de la esfera individual a la esfera colectiva sin mayores precauciones. Me interesaría ver la opinión de Liborio al respecto. Y respecto la definición conceptual de los derechos como algo distinto a sus técnicas normativas de protección, creo que ello viene en el mismo paquete que la teoría del interés o del bien. Si un derecho se define centralmente por el bien que protege y distribuye, entonces puede distinguirse el bien de sus formas de protección. En la teoría de Raz, en la que yo me inspiraba entonces, el bien o interés podría ser la «razón» por la que se establece la protección y la habilitación normativa. Ello no significa que lo que se contiene en la Declaración Universal sea un mero listado de «técnicas de protección». La declaración establece un conjunto de derechos en sentido estricto, es decir, un conjunto de bienes personales que han de distribuirse universal, igual e individualmente y protegerse mediante la técnica normativa de atribuir a los individuos competencias, inmunidades, acciones y permisiones. Liborio tiene razón en que los contextos a veces modulan estas cosas, pero solo las modulan: en Finlandia la calefacción es un bien que fundamenta una protección normativa acentuada (de hecho hay programas públicos de suministro), pero en Costa Rica no es necesaria tal cosa. Pero no avancemos de nuevo hacia el relativismo.

Y vamos con la «preocupante delgadez» del imperio de la ley. Me dice Luis que unos requisitos tan formales como los que propongo (reglas generales y abstractas, no retroactivas, razonablemente estables, etc.) no merecen el nombre de ética, ni siquiera mínima. Y tiene razón cuando dice que con una regulación así pueden cometerse graves injusticias. Y me pregunta, literalmente, si esa delgadez del imperio de la ley, «ayuno de derechos humanos», no traicionaría el valor tan central que concedemos a la autonomía personal. Lo que pienso es que si la regulación jurídica de las interacciones humanas no cumple con esos requisitos formales, para entendernos, los requisitos de FULLER, entonces no es posible la autonomía personal. Lo que no significa que la 
autonomía equivalga a esos requisitos. Creo que FULLER se equivocaba al tratar de definir el derecho a través de ellos. Pueden tomarse uno a uno y comprobar que muchos ordenamientos jurídicos los han traicionado. Pero lo que puede afirmarse es que sin ellos no es posible, no un derecho, sino un derecho justo (en el sentido de que sea un derecho protector de la autonomía). Solo son condición necesaria, no por supuesto condición suficiente.

Quiero ahora, enlazando con estas preguntas, comentar tres aportaciones de mucha hondura sobre los fundamentos de mi propuesta en el libro El imperio de la ley. Son de ese tipo de argumentaciones que hacen temblar los cimientos de todo el libro. Las de Juan Carlos BAYÓn, Marisa Iglesias, Isabel LifAnTe y Juan Manuel PéreZ BERMEJO. Algunas de ellas tienen algo en común: una apuesta explícita en favor de los principios frente a las reglas. Corrijo: una apuesta en favor de una mayor presencia de los principios en la argumentación jurídica. Pero en todas ellas pueden encontrarse notas y apuntes extraordinariamente ricos.

El nivel de concentración, precisión, información e inteligencia que tienen los escritos de Juan Carlos BAYÓn hace de ellos siempre textos de referencia. A nadie puede extrañar que resulten para él difíciles de engendrar. Por eso es para mí, en este caso, ocasión de un agradecimiento muy particular tener ese texto entre mis manos. Juan Carlos logra en su breve escrito poner de manifiesto una amenaza que habita el interior de todo mi libro: la amenaza que pudiéramos llamar de la rigidez. Y no le falta razón. Por haber forzado quizás demasiado las cosas para defender un ideal moral que me parece imprescindible, he podido sugerir un juez que parece más bien un artilugio mecánico, una visión de los planes de vida que suena más bien a programas automatizados, una predecibilidad propia de una divinidad omnisciente y un tipo de normas que tendrían que definir su ámbito de aplicación con una precisión milimétrica. Y lo que me recuerda Juan Carlos es que esas cosas pueden ser, en unos casos imposibles y en otras indeseables. Y todo ello, sin embargo, manteniendo el ideal en cuestión. En concreto se interroga sobre el peso que pueda tener la predecibilidad en mi argumento y sobre el tipo de juez que parece derivarse de él. Yo partía de una posición que creo que sigue siendo correcta: si vamos a dar cierto protagonismo a los planes de vida de las personas entonces un alto grado de predecibilidad es condición necesaria para sustentar ese protagonismo. No recuerdo de quién es la idea aquella de que habitar en una isla con un monstruo que amenaza con devorarte inesperadamente a cada momento es algo que excluye la autonomía personal. Simplemente no puedes planear nada. Y, por otro lado, en la vida humana no puede excluirse del todo el azar y la suerte (buena y mala). Teniendo todo esto en cuenta yo asignaba a la predecibilidad un papel importante en la construcción del ideal del imperio de la ley. Y, como es sabido, argumentaba que un buen orden jurídico que modulara las expectativas de conducta de los demás y del poder mismo era muy importante para que ese papel se cumpliera. Yo creo que esto se debe seguir manteniendo. Pero Juan Carlos hace notar que, desde luego, además de esa predecibilidad es necesario adscribir al sujeto unos derechos y libertades. Yo acepto esto, aunque solo sea por la obviedad de que poder predecir interferencias indeseables en tu vida y calamidades de todo tipo es un consuelo bastante pobre. Que lo puedas predecir mejora poco tu condición. Así que, en efecto, no se pueden pagar ciertos precios por esa predecibilidad. Y en concreto 
no se pueden ceder derechos básicos por ella. Hay que pensar en el ejercicio de los derechos en un mundo predecible en alto grado. Y lo que Juan Carlos señala es que quizás este diseño no se consiga mejor si para hacerlo nos empeñamos (me empeño) en hacer de las reglas redactadas con precisión las protagonistas del orden jurídico. No es posible que las reglas prevean con acuidad circunstancias futuras que se pueden dar y que exigen asumir grados de imprecisión y apelaciones a razones subyacentes a las reglas. No es difícil estar de acuerdo a priori con esto. ENDICOTT y SHAPIRO —a los que Juan Carlos apela - han señalado efectivamente que la vaguedad y la informalidad pueden tener también sus consecuencias beneficiosas en términos de imperio de la ley, pero mi escepticismo ante el éxito de la búsqueda de esas razones me hace quizás más precavido. Por eso me gusta la propuesta de lo que llama Juez deferente (frente al juez principialista y frente al artilugio mecánico que parecía surgir de mi construcción). Pero si se interpreta efectivamente, como alguien que «profesa lealtad a la ley» aunque pueda ver en un momento que su «aplicación estricta lleva a resultados contrarios a sus razones subyacentes». Y se tienen entonces las precauciones razonables y las motivaciones exigibles a la hora de establecer la premisa que refleje esas razones subyacentes. Mis precauciones me inclinaban a buscar en la coherencia genérica con el orden jurídico el camino de esa búsqueda; quizás no se puede ser tan tacaño como lo era yo, guiado por mis viejos temores al Estado arbitrario. Seguramente es necesario aceptar esas razones subyacentes. Una de las ventajas más evidentes que tiene trabajar junto a Juan Carlos BAYÓN no solo es lo mucho que se aprende de él (predominantemente por vía oral), sino esa limpia habilidad que tiene para tomar tus propias teorías, mirarlas y devolvértelas mejoradas, como redimidas de sus defectos evidentes. Esto ha sido para mí una experiencia impagable.

Marisa IGLESIAS también es uno de estos casos. Ella interroga al libro desde una dicotomía que aclara mucho las cosas, pero que quiero poner en cuestión y mejorar: frente a mi concepción, la concepción-libro de reglas, opone la concepción-orquesta de normas, incluso orquesta bien afinada de normas. Ahondando en su metáfora musical, no sé muy bien si a veces no se desliza hacia el error de confundir dos cosas heterogéneas: la partitura y el intérprete. Yo me ocupaba sobre todo de recomendar que se tocara con una partitura, la del código o libro de reglas, frente a otra partitura, la del libro de principios, que usaba como experimento mental. Y tenía cierta desconfianza (luego hablaré de ello a propósito del trabajo de PÉREZ BERMEJO) no tanto hacia algunos músicos (aunque también), como hacia las condiciones en las que tienen que tocar. Esta metáfora, por cierto, me trae el recuerdo de Albert CALSAMIGLIA, que vivía en la vida cotidiana un medio ambiente muy musical y con el que alguna vez discutí la comparación de la interpretación jurídica con la interpretación musical. Siempre me pareció una comparación difícil, porque las notas son prácticamente intemporales y el significado de las palabras no. Lo que cambia en la notación musical son los principios de su uso: el principio de obra y el principio de ejecución. Hasta alrededor de 1800 se utilizaba el principio de obra: lo que había que tocar era la notación impresa en la partitura. Después se va imponiendo el principio de ejecución, pues la notación va acompañada de ciertos indicadores sobre su ejecución (tomo estas acotaciones tan eruditas de un texto de Nicolas HARNONCOURT, solo para recordar a Albert). Sinceramente, no sabría cómo aplicar esta idea a la interpretación jurídica. Lo que yo pretendí hacer en el libro era rechazar la idea de que podrían resolverse los conflictos jurídicos a golpe 
de principios, dada la abstracción y la indeterminación de estos. Seguramente me pasaba de frenada, pero sigo teniendo la convicción de que hay que frenar bastante. No en balde se sigue manteniendo una actitud parecida a la mía en el campo del derecho penal y del derecho fiscal.

Las observaciones de Marisa me parecen convincentes excepto por lo que respecta a su conclusión: que las fisuras que ella pone de manifiesto en el modelo-libro de reglas pueden saldarse con el otro modelo. Si el primer modelo plantea problemas de imprevisibilidad y déficits democráticos, entonces el segundo también lo hace. Quizás debamos resignarnos a usar cláusulas vagas («en la medida de lo posible», etc.) porque es difícil alcanzar horizontes más precisos. Y el recurso a los principios solo puede llegar a ellos en el mundo encantado de los jueces ideales (orquestas «bien afinadas» y grandes músicos)

Pero vayamos a los temas concretos que ella examina, el de la previsibilidad y el de la democracia. Respecto al primero, ya he mencionado algo antes, y después me las veré más directamente con Isabel LIFANTE, pero hablemos ahora de YENTL. En el ejemplo de YENTL, una chica judía que quiere estudiar el Talmud en una comunidad con una regla muy estricta de prohibición de género para esos estudios, resulta que ve, efectivamente, cómo su plan de vida, es decir, su decisión autónoma (estudiar el Talmud) se ve imposibilitada, y no fomentada, por la regla estricta. Ergo, la previsibilidad no es siempre condición de la autonomía. Pero ¿es este un buen ejemplo? Me parece que no. Marisa IGLESIAS sitúa la acción en un contexto de clara injusticia, y entonces como hemos visto antes con Juan Carlos BAYÓN-la previsibilidad de que te apliquen una norma injusta no fomenta la autonomía, ni la igualdad, ni nada. Está, me parece, fuera de los límites morales que pretende proteger el ideal del imperio de la ley. La necesidad de un rango «razonable» de opciones abiertas ante uno, postulada por Marisa (y por Raz), es, desde luego, una suerte de condición de posibilidad del concepto mismo de autonomía, cuando no una propiedad incluida en su componente de libertad negativa. Pero lo que la proporciona no es lo que llama «flexibilidad normativa» sino un contexto de justicia más allá del imperio de la ley. En contextos cerrados de cultura religiosa la autonomía tiene muchas dificultades, no digamos si se trata de la autonomía de las mujeres. Lo que habría que decirle a YENTL, y a tantas otras, es que la religión no ha sido nunca compatible con la dignidad de género, así que mejor no malgastar su talento en tales estudios.

La otra consideración afecta a la convivencia entre previsibilidad y democracia: Marisa IGLESIAS dice una cosa un poco inquietante para mí. Cito: «una ley que, gracias a su alto grado de previsibilidad, consigue petrificar hoy la solución normativa de situaciones que se darán en el futuro cuando $a$ ) su reforma puede ser ardua, y $b$ ) encapsula realidades y circunstancias complejas o que pueden variar con rapidez, arrastraría en algún grado la objeción democrática, incluso siendo la ley el producto de la representación democrática». Su consejo: «que regulemos a través de principios, estándares o reglas con conceptos valorativos, que se adaptan mejor a las necesidades del presente». Pero ¿no se hurtaría a la exigencia democrática la regulación mediante principios o estándares vagos? Y ¿estamos seguros de que usar principios, estándares o valores es una variante de lo que HART aludía como «comunicar pautas generales de conducta que, sin necesidad de nuevas instrucciones, puedan ser comprendidas por multitud de 
individuos como algo que les exige cierto comportamiento en ocasiones determinadas»? Porque HART continuaba diciendo que sin este tipo de pautas no podría existir nada de lo que hoy reconocemos como derecho. Y las observaciones de Marisa, como en general toda la tendencia actual hacia la jurisprudencia de principios, proyecta todo el fenómeno jurídico al momento de la solución de un caso ante el juez, olvidándose al parecer de toda esa actitud cotidiana de los ciudadanos de obediencia a las normas que caracteriza la existencia del derecho. Y, lo que es más dudoso para mí, supone que los jueces, recurriendo como razones para sus fallos a esos tipos vagos de regulación, acertarán a adaptar las normas a los cambios mejor y más deprisa que un legislador democrático.

En fin, enfrentémonos ahora con una papeleta difícil: la radiografía de la previsibilidad que envía Isabel LIFANTE. Me alegra encontrarla aquí, porque cuando la examinó por primera vez, en un artículo que después publicaría en Doxa, 36, tuvo la amabilidad de enviarme una primera versión, con la mala suerte de que me llegó en plena mudanza y cometí la descortesía de no contestarla. Espero poder redimirme ahora. Isabel hace un planteamiento de los problemas de predecibilidad de las decisiones jurídicas que a mí me parece convincente. Lo que se propone mostrar es que la previsibilidad o predecibilidad del derecho obtenida solo a partir de rasgos formales, es insuficiente, o que los rasgos formales resultan muy pobres para generar previsibilidad. Para ello disecciona minuciosamente la noción de previsibilidad y muestra que fiarla a rasgos como la competencia, la formulación lingüística o el tipo de argumentación, resulta claramente insuficiente. En primer lugar, la previsibilidad respecto del qué, es decir, respecto de qué es lo que ha de ser previsible o predecible, no se consigue solo a través de esos rasgos, porque hay muchas veces que, como sucede en las reglas de fin (p. e., el bienestar del menor), los caminos normativos para alcanzarlo no están predeterminados. No puedo estar más de acuerdo. La subsunción pura y simple presupone el establecimiento de las premisas y para ello se necesitan casi siempre razonamientos teleológicos y ponderación de circunstancias y valores. Pero también hay que recordar que sin algún rasgo de carácter formal, como por ejemplo, la competencia del órgano decisor, no cabe predecibilidad alguna. Y además, me parece que el esqueleto básico de la subsunción debe subyacer a toda esta actividad, es decir, que una vez utilizados los razonamientos de todo tipo necesarios para sentar las premisas, se ha de proceder subsuntivamente.

Después viene el quién. ¿Quiénes son los que han de poder prever o predecir? Hay un dato objetivo de las sociedades «bien ordenadas» jurídicamente que siempre me ha parecido enigmático. Si uno vive en Alemania, en seguida se da cuenta de que los ciudadanos cumplen las leyes. Cómo pasa una norma de la Gaceta a la realidad cotidiana es algo que siempre me ha producido perplejidad. Porque es evidente que solo una mínima parte de esos ciudadanos «conoce» el derecho, por clara que sea su formulación, estricta su coherencia, etc. Y sin embargo, cumplen con él. Pues bien, aquí no me parece tan convincente la respuesta de Isabel LIFANTE: pretende que esa actitud general pueda derivarse de los principios subyacentes a las normas o a su coincidencia con los modos de vida. Respecto de lo primero, ya sabemos que tengo mis dudas sobre que quienes encuentran dificultades en la idea de autonomía semántica de las normas, vean tan sumamente fácil descender sin problemas a los principios que las subyacen. Si las 
oraciones son difíciles, los valores y su alcance no digamos. Intuitivamente me parece más difícil identificar el principio subyacente a una regla que el significado explícito de la regla, y en todo caso, me parece imposible hacerlo sin conocer ese significado. Esto no quiere decir que las reglas sean siempre claras y terminantes. Lo que quiere decir es que para establecer su significado se proyectan sobre ellas valores subyacentes que son muchas veces tomas de posición a priori del intérprete. Y por lo que respecta a la previsibilidad, tampoco me parece que se consiga en gran medida con ello. Quizás sí, si, como escribe Isabel, hay una proximidad entre la norma jurídica y las normas sociales, pero eso es contingente. Muchas veces las normas jurídicas se dirigen precisamente a alterar rutinas sociales injustas o anticuadas.

Y respecto a la perdurabilidad o estabilidad de las normas, como las quejas cotidianas de los operadores jurídicos y de los académicos son tan insistentes, me ahorran cualquier observación. ¡Cuántas veces no se ha oído decir que aunque la regulación sea mala es preferible que la dejen como está y no la alteren otra vez! Isabel LIFANTE sugiere que la presencia de ciertos objetivos valiosos daría una cierta continuidad a la práctica social. Pero aquí me vuelvo a sentir escéptico. Lo que genera con frecuencia la inaguantable mutabilidad de las normas son intereses sectoriales que presionan sobre el legislador, y esos intereses no tienen en mente los objetivos valiosos de la comunidad, si es que la discusión no versa precisamente sobre ellos.

Por su parte, Juan Manuel PÉrez BERMEjo en el seno de un breve trabajo también muy denso, me interroga sobre extremos interesantes pero difíciles. Me pregunta si el ideal moral de autonomía personal que pretende operar como premisa de toda la conclusión es una premisa moral «comprehensiva» y si es «fundacional». Esto ya me lo había preguntado alguien, pero tengo que confesar que ni siquiera me lo planteé al imaginar el relato del libro. En realidad me parece ahora que tampoco tendría que haberlo hecho, pues de lo que se trataba era de dar un apoyo moral a un tipo de orden jurídico, el orden jurídico liberal del estado de derecho. ¿Por qué defendemos el rule of law o el Rechtsstaat en el mundo contemporáneo? Pues porque protege la autonomía personal en los términos en que yo lo propongo. Posibilita en gran medida que las gentes adopten sus planes de vida y sus proyectos individuales y colectivos. Que esto incluya otras dimensiones del mundo moral, como las virtudes ciudadanas o la teoría del bien, o que promueva que el derecho se inmiscuya en la esfera íntima de las personas, son cosas que me parece están más allá de mi proyecto. Después Juan Manuel me pregunta si esa premisa moral es fundacional, en el sentido de ser el valor fundamental o último. Aunque tampoco me aventuraba por estos territorios, me parece, en efecto, que es al menos uno de los dos ingredientes que pueden operar de fundamento básico de una concepción de lo recto. El otro sería la igualdad de todos los seres humanos como agentes morales. A partir de esos dos valores, autonomía personal e igualdad moral, creo que se puede construir toda una concepción, no solo de la justicia, sino en general de lo moralmente recto. En las consecuencias de esta propuesta me temo que no puedo entrar ahora.

La lectura del libro de Scott SHAPIRO también me sorprendió a mí por el supuesto paralelo que podría tener con ideas del mío. Pero enseguida me di cuenta de que navegábamos en dos direcciones diferentes. SHAPIRO pretendía hacer una teoría del derecho: las normas fundamentales del derecho serían directamente planes, y las ins- 
tituciones, planes a priori. Así, recurriendo solamente a una intuición antropológica (que los hombres son criaturas planificadoras) podía dar cuenta del derecho, explicar el derecho, sin apelar a premisa moral alguna. Yo no trataba de explicar el derecho, ni de hacer una teoría del derecho; solo trataba de justificar una particular disposición del orden jurídico, el imperio de la ley, o, si se quiere, el Estado de Derecho. Es decir, acudía a una premisa moral externa al derecho, la autonomía personal como valor moral, para postular que el derecho se diseñara de una cierta manera. Tengo una cierta concepción del derecho, pero no es eso lo que buscaba explicar o justificar.

Por último Juan Manuel PÉREZ BERMEJO comenta sobre la posición mía respecto de la interpretación, y del diseño institucional que se derivaría de mi visión del proceso interpretativo. Respecto de la interpretación no puedo detenerme aquí, pero sí diré que sigo teniendo la misma perplejidad respecto a la relación entre formulación normativa y norma, y que esa perplejidad solo se disuelve si pienso en la interpretación literal. Esa me parece además que es la manera más clara de pensar en el sometimiento del juez a la ley. Naturalmente, creo no ignorar todas las dificultades que eso tiene. Y ello, y ahí tiene razón Pérez BERMEJo, me lleva a una, no la llamaría yo desconfianza, sino reubicación del rol del juez en la práctica del derecho. Ya he dicho alguna vez que el dworkinismo y el neoconstitucionalismo han empujado la decisión judicial al centro de la teoría y la práctica del derecho. Pero me parece que incurren en una idealización del momento de la decisión: juez esclarecido, información exhaustiva, carácter moral, sin límite de tiempo, etc. Y con ello, me parece, cometen la que ha sido llamada falacia del nirvana, a saber, fabular una situación irreal que no se corresponde con la realidad y presuponer que todo problema posible tiene una solución correcta, una right answer. Solo con estas premisas puede sostenerse el edificio teórico que se ha montado en torno a la decisión judicial. Y, como es sabido, no está tan claro que esas premisas estén destinadas a verificarse. De ahí viene mi desconfianza, no hacia los jueces, como a veces se me ha dicho, sino al aparato institucional de la administración de justicia como tal, con sus modos de formación y selección, sus procedimientos, sus increíbles atascos, sus medios, etc. Y esto vale también para los altos tribunales, no nos engañemos. Quizás la excepción sea la Corte Suprema de los Estados Unidos, pero es que conoce tan solo de sesenta o setenta casos al año, que son los que llegan por semana a muchos de los otros tribunales, por altos que sean.

José Juan MoRESO siempre anda entre problemas teóricos interesantes. Y se los plantea a los demás. En este caso a nosotros. El primero de ellos, que confieso no haberme planteado hasta este momento, es el de la naturaleza de las prescripciones abstractas. Tomando como base la clasificación de las normas de BOBBIO, yo encontraba que había normas abstractas y concretas. Las abstractas eras aquellas que regulaban un act-type y las concretas las que regulaban un act-token. BOBBIO llamaba a estas últimas «órdenes». Es decir, asumiendo la distinción act-type/act-token (a la que se puede agregar la distinción paralela fact-type/fact-token) presumía que puede haber normas que regulen un acto-tipo y normas que regulen un acto-concreto. $Y$ en consecuencia, afirmaba que para cumplir con los requisitos del rule of law, las prescripciones, las normas, tenían que ser abstractas en este sentido (los tipos penales, los hechos imponibles, etc.). Pero José Juan nos viene a decir que todas las prescripciones son abstractas, lo que equivale a decir que el contenido de una prescripción no puede ser nunca un act- 
token. Casi se deriva de sus palabras, y de un correo electrónico que nos envió después, que los acts-token en realidad no existen o no pueden ser expresados con palabras; eso sí, con dos excepciones relevantes: los actos o hechos pasados, que podemos identificar, y las circunstancias espacio-temporales de un hecho, de las que sí podemos hablar. Este problema me parece que no afecta a la construcción teórica del imperio de la ley, como le afectaría que no existieran o no pudieran ser expresadas las acciones tipo o acciones abstractas. Es, pues, un tema que, como todos los que suscita José Juan, nos invita a salirnos de los límites de nuestra disciplina y navegar en el mar abierto de la filosofía. Me encanta esto. Veamos: ¿es que acaso, por problemas lógicos, no podemos anticipar un acto de una persona o un hecho natural o social? ¿ $\mathrm{O}$ es solo un problema de lenguaje? ¿Nuestra capacidad predictiva es una ilusión? ¿O solo sucede que no podemos formular nuestras predicciones? Y más ¿cómo podremos decir de algo, de un acto, que «encaja» o es un ejemplo de determinado act type? Estas cosas me parecen de la máxima importancia, porque tengo como un axioma que lo que diferencia al ser humano de otros animales es precisamente su capacidad de predecir acontecimientos futuros e identificar actos presentes. Es, obviamente, una capacidad restringida: nuestra información es limitada, y los contextos en que la usamos muy complejos a veces (este es tema muy querido por los economistas). Por las palabras de José Juan, deduzco que se trata solo de un problema de lógica del lenguaje, que se supera una vez que el acontecimiento se desplaza al pasado. Entonces podemos identificarlo y formularlo. Esto explicaría por qué somos tan eficaces en las predicciones ex post, es decir, en las post-dicciones. Pero me plantea un problema. La única razón por la que podemos identificar un acto o hecho del pasado (como lo hacen los tribunales todos los días) es que la historia, por así decirlo, nos suministra todas las circunstancias de contexto, que en la mayoría de los casos damos por supuestas y no mencionamos en la descripción del hecho pasado (por ejemplo, que el asesino iba vestido) a no ser que sean relevantes para el hecho mismo (el asesino, que estaba vestido, había irrumpido en una playa de nudistas preso de su moralismo fanático). Pero esto me parece que también puede suceder cuando anticipamos un hecho, y cuando formulamos verbalmente esa prognosis: damos por supuesto y no nos paramos a mencionar todos aquellos elementos del contexto que son irrelevantes para el hecho. Si es esto lo que hace necesariamente abstractas a nuestras predicciones (y a nuestras prescripciones), entonces puedo aceptarlo. Pero si se trata de una mera imposibilidad lógica de formularlas, entonces no me parece tan convincente. Como vemos es cosa que pide más espacio y más tiempo.

La otra observación de José Juan es más familiar para los que le leemos habitualmente. Se trata del protagonismo de los defeaters en el momento de aplicación del derecho. Los defeaters, dice José Juan, establecen excepciones a las reglas generales y permiten acudir a las razones que justifican esas reglas. Mis dudas con ello se refieren a problemas de identificación de la solución normativa en esos supuestos. Podemos tener problemas de identificación de eso que llamamos «excepciones», y podemos tener problemas de identificación de los que presumimos valores subyacentes a las reglas. El primero de esos problemas versa sobre si el caso cae bajo el alcance de la norma, y lo que decimos en ciertos supuestos es que, efectivamente, cae bajo ese alcance pero se trata de algo excepcional que no debe ser regulado por ella, y para concluir esto, abandonamos las palabras de la norma para sumergirnos en las razones que la subyacen. Y ahí viene el segundo problema: cómo identificamos el principio o valor que opera 
como razón de la norma. Si lo hacemos bien, disponemos de una herramienta preciosa, como la regla de plomo de los arquitectos lesbios, que se adaptaba a la forma de la piedra. Pero si lo hacemos mal podemos estar utilizando también una herramienta ventajista, que incluya o excluya arbitrariamente un supuesto del alcance de la norma, y proyectando sobre él una justificación que improvisamos. Cuándo lo hacemos bien y cuándo mal es algo que no es tan fácil de deslindar. Y de ahí surgen mis inquietudes.

José Luis CoLOMER escribe, con razón, que en tres mil palabras es difícil saldar la cuestión del lugar de la autonomía personal en el universo moral y político, pero creo que acierta al plantear tres puntos cruciales que la idea de autonomía implica. Estoy seguro de que me disculpará por lo sucinto de mi respuesta, dado que mi cupo es de mucho menos que tres mil palabras. Con toda modestia ante un especialista en KANT como él, creo, en primer lugar, que no he confundido la idea kantiana de autonomía como una propiedad de los juicios morales (ausencia de determinación por dimensiones empíricas) con el principio de autonomía que manejo (cfr. El imperio..., p. 26, nota 12), aunque no es imposible que inadvertidamente los haya aproximado demasiado en algún momento. Entiendo la autonomía en un sentido diferente y mucho más amplio, como la capacidad libre de articular el propio plan de vida. Por cierto que incluyo en ella la afirmación del libre albedrío, como condición de posibilidad de la vida moral, pero apenas nada más de la idea kantiana. Es una idea más compleja: incluye la libertad negativa, la racionalidad de las creencias, la proyección en el tiempo, y los planes de vida. Es obvio que todas esas cosas no se pueden extraer del punto de partida kantiano. Se trata de una premisa de una concepción de la justicia o de una hipótesis de antropología moral. Esta premisa, por cierto, no identifica sin más mi teoría como una teoría monista. Ya he tenido que contestar a esta observación. No soy monista si por monismo se entiende que hago descansar todo el discurso moral sobre un solo valor. He afirmado que se necesitan al menos dos, que pienso no pueden entrar en conflicto: el valor de la autonomía y el valor de la igualdad esencial de los seres humanos como agentes morales. Y creo, sí, que a partir de esos dos «axiomas» pueden derivarse los derechos morales básicos sin mayores dificultades hasta componer, como muy bien ha sugerido Liborio, una teoría de la justicia. José Luis arguye que es difícil pensar que un meta-valor como ese (o como esos) pueda servirnos de criterio para resolver los conflictos o contradicciones de derechos, pero es posible también que un universo complejo de demandas como las que se encierran en el principio de autonomía pueda dar lugar a contradicciones difíciles de resolver. Esto lo digo con mucho cuidado, porque no estoy nada seguro de ello, pero su objeción parece basarse en la imposibilidad de los dilemas morales genuinos, y yo me inclino más bien por aceptarlos resignadamente. Después sugiere que la conexión entre autonomía e imperio de la ley es un tanto forzada, pues registra una «distancia importante» entre la necesidad de regularidades de conducta (y por tanto de órdenes jurídicos) y la exigencia que yo planteo de decisiones judiciales predecibles en algún grado. Me parece que si necesitamos las regularidades de conducta, también necesitamos que las normas que las posibilitan se apliquen predecible y coherentemente. Pues en caso contrario ¿para qué sirven las normas? Creo ser consciente de que la evolución de las circunstancias y los contextos puede exigir de un aplicador del derecho que module el alcance de la norma, o directamente, que llame la atención sobre una posible situación de anomia, pero me esfuerzo por enlazar más los jueces a la norma que en alentar su manejo de los principios. La predecibilidad 
es un corolario de la autonomía, y para mostrarlo no se pueden, obviamente, dar saltos argumentales arbitrarios, pero confío en que pueda caminarse racionalmente de una cosa a la otra sin incurrir en algún non sequitur.

Y aparece por último el tema de las relaciones entre autonomía y democracia. Aquí es donde voy a hacer comparecer a Alfonso RuIZ MiguEL, porque ello puede dar lugar a una paradoja interesante. José Luis afirma en su escrito - haciendo una observación sobre todo a Liborio- que no ve nada clara la fundamentación de la democracia en la autonomía individual. Plantea sin duda preguntas muy pertinentes que, sin embargo, no hay lugar para contestar aquí. Muchas dimensiones de la democracia como articulación institucional de la toma de decisiones parecen muy distantes del axioma de la autonomía individual. Yo creo que con una argumentación lo suficientemente rica se pueden reconducir a ese axioma, pero, naturalmente, no puedo intentarlo aquí. Lo que me sorprende es que Alfonso RuIz Miguel, al final de su amable escrito «a modo de presentación» suscite precisamente una idea que parece ir en dirección contraria a la de José Luis. Apoyándose en mis inveteradas críticas a los referendos y plebiscitos, y a una sugerencia de Luis RODRÍGUEZ ABASCAL, viene a afirmar que al intentar prescindir de los aspectos negativos de la democracia directa, acabo por tirar el bebé con el agua sucia, es decir, acabo por tirar la democracia misma con el agua sucia de sus impurezas. Y ello no se compadece con mi defensa de la autonomía personal como fundamento de la democracia. Prescindir del plebiscito es abandonar también la idea de que la autonomía personal ha de ser respetada como principio fundante. Como se ve dos objeciones que viajan en direcciones opuestas. COLOMER me dice que no se puede viajar desde la autonomía a la democracia. RuIZ Miguel que no se puede negar la democracia directa si se afirma la autonomía. Veremos cómo salgo de esta. La primera parte me parece intuitivamente más fácil: si se considera a todos los ciudadanos como iguales y autónomos, una manera clara de hacer reales esos valores es aceptando su participación — directa o indirecta - en pie de igualdad en la elaboración de todas aquellas políticas que puedan afectar o condicionar sus planes de vida. La vieja idea de que en el proceso democrático uno se obliga a sí mismo parece intuitivamente cercana a la idea de autonomía individual. Lo que es más difícil, me parece, es afrontar el tramo argumentativo de Alfonso: es decir, afirmar que el individuo ha de ser autónomo y privarle al mismo tiempo de la posibilidad de participar en la decisión directa vía referéndum de algo que puede afectar a su plan de vida. Lo que yo veo como una salida posible a esta endemoniada pregunta es que no planteo las cosas como un aut-aut. O referéndum o nada. Podemos mantener, creo, que la decisión haya de ser tomada por una asamblea compuesta por delegados en cuya elección haya participado el ciudadano. Y este me parece a mí ser el mejor método para tomar decisiones complejas sin menoscabo de la autonomía individual. Cuando se trata de ese tipo de decisiones, en cambio, el procedimiento tosco del referéndum, el de unir las preferencias en dos alternativas excluyentes, genera disfunciones, malentendidos, coaliciones no queridas de minorías, etc., que han sido muchas veces denunciados como irracionales e imprevisibles. Eso por no mencionar que la puesta en práctica de unas condiciones mínimamente razonables de reflexión y deliberación en tal tipo de consultas es hoy por hoy casi imposible. La capacidad para establecer una comunicación sin excesivas poluciones y llegar con una mínima información y criterio a la razón del ciudadano (que, no se olvide, es para mí también un ingrediente de su autonomía) es prácticamente nula. Las sociedades 
muy complejas y plurales solo admiten democracias representativas, y aún estas están pasando hoy por momentos oscuros que exigen su urgente reconsideración. Pero este, claro está, no es tema para estas líneas de agradecimiento.

Creo que este es el lugar para discutir el «tema menor» que nos plantea Elena BELTRÁN. El tema de la dignidad humana. Para ser justos con ella hay que recordar que lo que dice es que es un tema menor en nuestra obra, especialmente en la mía. Pero como suele acontecer con las ideas morales «vagas y poderosas», en mis acercamientos a los derechos humanos y al imperio de la ley andaba siempre rondando por ahí la idea de la dignidad humana. Mi referencia a PICO DELLA MIRANDOLA es canónica a este respecto. La dignidad parece consistir, según él, en que el ser humano puede ser lo que quiera, es decir, en el libre albedrío y la autonomía personal. Pero yo no me atrevería a decir si es un valor moral previo a los derechos y los fundamenta y explica, o si es simplemente el conjunto de esos derechos, o al menos de algunos de ellos. Por la primera opción se pronunciarían gentes tan serias como RAWLS (el bien del auto-respeto se aproximaría a eso) y Avishai MARgaLit (la idea de la exclusión de la humillación en la sociedad decente también se parece a ello). Por la segunda, WALDRON, al parecer, y el Tribunal Supremo de Canadá. Creo que también se inclinaría por ella alguien que la analizara como un concepto jurídico del tipo Tû-Tû. No conozco el trabajo de WALDRON, pero en 1992, en un homenaje al Justice BRENNAN, se reunieron una serie de ensayos sobre ese tema [The Constitution of Rights. Human Dignity and American Values. M. J. MEYER y W. A. PARENT (eds.), Ithaca, Cornell University Press, 1992] y no me atrevo a afirmar que resolvieran la duda. En la dignidad humana siempre parece haber algo anterior a los derechos, que les sirve, si no de fundamento, al menos de fulminante para su entrada en acción. Y, puesto a pensar en ella, creo que tiene las dos dimensiones que señala Elena: una dimensión de igualación, la que rompe con la estratificación de dignidades de la sociedad premoderna, y una dimensión de libre albedrío y responsabilidad, la que acuñó Pico y después consagró KANT. Esas dos dimensiones coincidirían con los dos valores que he dado como respuesta antes cuando se me preguntaba si para mí la autonomía personal era un valor «fundante» o único. Como he dicho, siempre he pensado que a su lado tendría que ir el valor de igualdad de los seres humanos como agentes morales. Y puede verse ahora que esos valores expresan precisamente las dos dimensiones de la dignidad humana. No he leído el trabajo de WALDRON que trae a colación, pero la presentación que hace Elena de él me hace dudar. El concepto de estatus no añade demasiadas cosas si, como afirman los sociólogos, no es más que un haz de derechos y deberes, una posición en la vida social definida por las normas que ha de cumplir quien la ocupe.

Macario Alemany enfoca su aportación hacia un tema que me parece particularmente interesante. Recuerda que tanto Liborio HIERRO como yo hemos defendido la idea de universalidad de los derechos humanos, y que ello tiene algunas consecuencias que hay que examinar. La primera, naturalmente, que ya he mencionado, es que los derechos humanos se residencian inicialmente en el discurso moral, puesto que —si uno no es un iusnaturalista de cierto tipo- no puede aceptar que exista un orden jurídico universal. Los derechos humanos son inicialmente derechos morales básicos. La segunda, que es la que más le interesa, es que un corolario de esto es que esa universalidad de los derechos morales básicos se proyecta también sobre los obligados, ya que 
fundamenta obligaciones generales y deberes positivos generales. Esta es ciertamente una conclusión importante. Y enlaza además con mi posición en relación con los deberes positivos generales, una posición que dibujé en diálogo con Ernesto GARZÓN VALDÉS también hace ya años. Como bien señala Macario, si esos deberes morales quieren evitar objeciones letales (por ejemplo, que producen problemas severos de ineficiencia por ausencia de coordinación o que tienden a transformar en héroes o mártires a todos los agentes morales, al exigirles como debidas conductas supererogatorias), tienen que mutar a deberes positivos especiales o de rol mediante la existencia de instituciones organizadas de protección y cumplimiento de esos derechos, de forma tal que, cada uno, al cumplir con su deber especial en la organización, cumpla con su deber positivo general. Y entonces Macario se hace — nos hace- la gran pregunta. Si esto es así, entonces esos deberes han de producir una transformación institucional del derecho, pues van a requerir de él que supere aún más las fronteras estatales y se establezca en el ámbito internacional: por ejemplo, un sistema impositivo redistributivo de ámbito global o una jurisdicción internacional seria. La vieja noción de soberanía va a deteriorarse aún más. Estoy de acuerdo con el planteamiento. Así es cómo se debería proceder. Otra cosas es que sea optimista al respecto. No lo soy. Creo que para que se dé algo así como una institucionalización jurídica de los deberes morales de solidaridad se necesitan acometer tres tareas: primera, redefinir la responsabilidad de los gobiernos estatales en términos de responsibility to protect (Informe de la Comisión Internacional sobre Intervención y Soberanía del Estado. ONU, 2001); segunda, que se flexibilice y limite el principio internacional de no intervención; y tercera, que se organice, en coordinación con los Estados, una fuerza coactiva para aplicar las disposiciones internacionales. Esto, no hay que decirlo, es un cambio fundamental de la percepción actual del derecho internacional, y sobre todo, de su práctica. No soy, como digo, nada optimista sobre ello. Creo más bien que un cúmulo de factores perversos en concierto se pueden transformar en concausas para la producción de un desastre ecológico, humano e incluso bélico de proporciones inimaginables. Pero no quiero estropear el clima afectuoso de este escrito recordándolas. Yo entiendo, por último, que Macario AlEmany, trabajando donde trabaja, tenga que acabar tratando de convencernos de que la solución puede estar en que nos apuntemos al postpositivismo y hagamos un cántico a la argumentación a partir de principios, pero eso me recuerda una noche que, cenando con ALEXY en Düsseldorf con ocasión de un homenaje a Ernesto, tardaron tanto en traernos la comida que nos bebimos dos botellas de vino antes de empezar y acordamos allí mismo, él y yo, frenar al Estado Islámico organizando... un congreso de filosofía del derecho.

Viene ahora muy a propósito del alcance de los deberes positivos generales que me ocupe del paper de Cristina SánCHEZ, querida colega de mi área con la que he tenido la oportunidad impagable de desarrollar durante estos años una asignatura de esas que se llaman transversales, dirigida a todos los estudiantes de la Universidad, sobre el Holocausto y sus problemas filosóficos, éticos y jurídicos. Si no fuera por la estúpida rigidez e inmovilismo que el llamado proceso de Bolonia ha introducido en todos los programas universitarios, este podría haber sido uno de esos proyectos que amplían la visión de nuestros estudiantes de derecho, porque tomar contacto con las particularidades del Estado nazi y sus fechorías ahonda mucho la comprensión de nuestros sistemas jurídicos. Pero nuestros estudiantes están proyectados para oficiales de notaría, en 
el mejor de los casos, y estas cosas no caben en ese proyecto. Así que Cristina, Evaristo PRIETO y yo, que éramos los que llevábamos la enseñanza (mucho más ellos que yo) hemos tenido que asumir a una mayoría de estudiantes extranjeros, algunos de ellos alemanes, y proseguir por puro interés personal. Fue Cristina SÁNCHEZ precisamente quien suscitó en mí el interés por el comportamiento de los «alemanes corrientes». Ideó un cuadro de actitudes de ellos: los que se rebelaron, los que fueron actores deliberados, los cómplices activos, los que cooperaron pasivamente y los que llamamos coloquialmente bystanders. Es una pena que no lo haya desarrollado teóricamente y lo haya publicado, porque es una herramienta de gran utilidad. Y fue entonces cuando me di cuenta de que mi posicionamiento ante la cuestión de los deberes positivos generales podría proyectarse sobre un fenómeno como el Holocausto, que funciona además como un «intensificador» (son sus palabras) de los problemas. Mi propuesta respecto al problema general, como he dicho, es que los deberes positivos generales se satisfacen mejor mediante la organización de estructuras que nos permitan realizar las acciones debidas coordinadamente y con límites, de forma tal que no sean ineficientes o declaradamente supererogatorias. Ahora Cristina me sugiere una perspectiva nueva, que toma de Iris Young: no solo hemos de actuar en el marco de organizaciones para cumplir nuestros deberes, sino que algo que se había revelado más difícil, establecer nuestra responsabilidad individual en los casos de omisiones masivas a escala trasnacional, también puede aclararse teóricamente recurriendo a nuestra participación más o menos deliberada en las estructuras y procesos que generan esas injusticias. Yo no soy responsable simplemente por mi omisión individual, sino porque mi vida y mi conducta están engarzadas en estructuras de injusticia que crean y potencian la vulnerabilidad de los demás. Ello posibilita además modular los grados de esa responsabilidad. Pero en el caso del Holocausto sigue presente el problema de siempre: en un contexto amenazatorio y vil como el que crea el III Reich, podemos seguir siendo responsables, pero el cumplimiento de nuestros consiguientes deberes depende de la creación de organizaciones (p. ej., la Resistencia) o la realización de acciones individuales que nos sitúan en contextos extremadamente peligrosos: las acciones debidas se transforman en supererogatorias, y, por tanto, no son debidas. Más allá de otras consideraciones más teóricas, estas reflexiones que hago con Cristina me confirman en mi convicción de que el más profundo mal que producen los regímenes dictatoriales y violentos (también los del terrorismo local) es precisamente el de generar el miedo que desactiva la realización de nuestros deberes morales básicos al exigir para ellos conductas heroicas. Cuando el miedo nos impide realizarlas, queda sin embargo allí abajo todavía la culpa y la vergüenza, una suerte de deshonor. Privar del honor moral al ciudadano es la máxima iniquidad de las dictaduras.

No quiero dejar de reflexionar un poco sobre algunos de los puntos (no todos) que suscita Gema Marcilla. Hace una presentación histórica densa del concepto de imperio de la ley y nos pregunta si todavía sobrevivirá en la sociedad globalizada. Me interesan en realidad tres puntos que toca en una ponencia de gran densidad. Los mencionaré, pero me parece que no podré contestarlos del todo. En primer lugar, si el concepto de imperio de la ley es un concepto histórico. Esta idea de concepto histórico la hemos heredado de don Felipe GONZÁLEZ VICÉN, y, con todo respeto, yo no la veo nada clara. Salvo que pensemos que existen conceptos intemporales, todos los conceptos son históricos en el sentido de que surgen en un momento histórico y se aplican a 
capturar algunos segmentos de la realidad de ese momento. Pero también son históricos en el sentido de que se van elaborando paulatinamente a lo largo de la historia del pensamiento hasta llegar a un momento clave de eclosión. Con «imperio de la ley» suceden las dos cosas: surge en el siglo XIX como rule of law o Rechtsstaat y su intuición puede rastrearse a través de la historia al menos hasta Platón o ARISTÓteles. Más dificultad me ofrece su dimensión normativa, o para decirlo claramente, su dimensión ética. Es este un problema muy de fondo. Si la mayoría de los valores morales se caracterizan por su pretensión de universalidad ¿cómo podemos restringirlos a un momento histórico dado? Si lo hacemos parece que introducimos inadvertidamente en el discurso moral una dosis de relativismo. Una segunda cuestión que sugiere Gema es que parecemos inspirarnos mucho en RoussEAU. Yo no me siento así del todo, pero eso lo tendré que hablar en algún otro lugar más despacio. Confesaré ahora públicamente que no me simpatiza RousSEAU. Aunque su obra me parece la de un genio, es ambiguo en muchos puntos fundamentales, y como persona debió ser inaguantable. La tercera idea que transmite es la de mi tendencia a limitar la «constitucionitis» que nos ha invadido estos años. Deploro decirlo, pero hemos abandonado la elaboración parlamentaria, y la discusión y deliberación de las leyes, y nos hemos entregado a la crónica constitucional. La creación de una ley en nuestras flamantes Cortes Generales es demasiadas veces el producto de unos cuantos forcejeos u ocurrencias entre lobbies informales de todo tipo y el gobierno, un acuerdo más o menos secreto entre partidos y un trámite en votación única. No son los jueces ni los principios los que están amenazando a la democracia, es la insultante incuria de nuestros gobiernos y nuestros parlamentarios a la hora de elaborar, debatir, comunicar y persuadir sobre el contenido de las leyes. Por no mencionar que, incluso con una mayoría absoluta, la pasada legislatura fue la que más recurrió al decreto-ley. Mala calidad técnica y nula deliberación pública hacen de nuestro parlamento una de las instituciones peor valoradas por los ciudadanos a los que se pretende que representen. Y por último, la pregunta de Gema sobre la supervivencia del imperio de la ley en un mundo globalizado. El problema de la globalización es que es una globalización financiera y cultural, pero casi nada más. Se avanza poco a poco en la homogeneización de algunas normas jurídicas, y ese es un camino que es preciso seguir, pero es comparativamente mucho más lento que la actividad financiera transfronteriza y el desarrollo de la sociedad de la información. En estas circunstancias, hablar, no ya de imperio de la ley en la sociedad global, sino de la mera presencia de la ley en ella, es ilusorio. Los progresos que se hacen mediante el soft law y los mecanismos de gobernanza son claramente insuficientes. Y con ello, naturalmente, dejan de estar protegidos todos los valores morales que lleva consigo el Estado de Derecho. Entre los objetivos del milenio figuraba la extensión y consolidación del rule of law, pero no parece que se adelante mucho. Repito que soy pesimista.

Pocas cosas me satisfacen más que debatir sobre problemas de educación. La contribución de Josep M. Villajosana me satisface por ello, y muestra además algunos puntos que deben ser al menos explicados. En primer lugar, tiene razón en que mi posición frente al llamado proceso de Bolonia puede tener alguna incoherencia. Quizás no maticé lo suficiente. Yo me enfrenté a Bolonia demasiado rotundamente, por tres razones. La primera, porque me pareció desde el principio que no debería aplicarse a los estudios de derecho; la segunda porque traía como efecto colateral una que llamaré manía «mensurativa» que creo que está fuera de lugar y socaba la autoridad del profe- 
sor; $y$ en tercer lugar, porque alardeaba de dar al profesor un rol distinto en el proceso educativo y al mismo tiempo lo ignoraba completamente. Además, me pareció siempre, antes de Bolonia y ahora, que para mejorar la universidad se necesitaban algunas medidas que no se tomaban (los cuatro «cascabeles» que nadie le pone al gato, como recuerda Josep María): selección de los estudiantes, limitación de su número en el aula, financiación seria de las universidades, y selección rigurosa del profesorado. Me dice entonces que si se dieran esas medidas, como se dan muy para su bien, en la Universidad Pompeu Fabra, entonces el método Bolonia no sería tan malo. Esa - dice- es su experiencia. Tengo a la Universidad Pompeu Fabra en muy alto concepto. Lo que de ella puedo apreciar me parece de excelencia. Pero sufre, como todas las demás esa falta de sensibilidad hacia el problema del profesorado joven. Mis ideas universitarias y pedagógicas se sustentan en un axioma fundamental, que enunciaron hace más de cien años Francisco GiNER DE LOS Ríos y Manuel B. Cossio en la Institución Libre de Enseñanza: «dadme el maestro y os abandono todo lo demás». La cuestión del profesorado no es, pues, para mí una más de las cuestiones sino la cuestión crucial. Da igual el método y las medidas, las calificaciones, los exámenes (que ellos odiaban) y la disciplina externa. Si hay un/a buen/a profesor/a, entonces todo está resuelto. Un buen profesor, naturalmente, es alguien con muchas propiedades, además, por supuesto, de la de ser un buen conocedor de lo que enseña, pero no puedo alargarme aquí en ello. La segunda razón de mi objeción al plan es que ha trasladado al estudiante un espejismo letal: que existe una medida exacta de comprobación de lo que sabe y lo que no sabe. Incluyendo hasta décimas y centésimas. Esto es simplemente falso. O empuja a la educación a un simplismo desmedido. El simplismo de los test. Quizás para transmitir una información extremadamente codificada pueda concebirse algo así. Pero para el derecho no. Yo entiendo que mis compañeros recurran a la utilización de test de control de conocimiento para no inmolarse ante un plan que les exige «evaluación continua» en grupos de cien estudiantes. Ya es bastante penoso que los cien se dividan en tres grupos de treinta, a cada uno de los cuales hay que hacer la misma «evaluación» en la semana, volviendo a decir tres veces lo mismo, y poniendo tres pruebas distintas. Pues bien, en primer lugar, la evaluación continua es precisamente lo contrario de los exámenes, sean o no tipo test. O exámenes o evaluación continua. Disyunción exclusiva. Si exámenes, entonces no evaluación continua; si evaluación continua entonces no exámenes. En segundo, lugar se pretende que el test dé un resultado algebraico preciso porque la puntuación es precisa. Esto no es más que una ilusión pueril de los pedagogos instrumentales. No es real, pero se lleva por delante la valoración (y el protagonismo) del profesor.

Pero no quiero acabar estas ideas de urgencia sin aludir al principal motivo que me oponía al plan Bolonia. Cualquier plan de estudios tiene que arrancar necesariamente de un punto de partida: qué clase de persona queremos que resulte de él. Y en particular, en los planes universitarios, qué clase de médico, arquitecto, psicólogo, etc., y jurista queremos. Lo único que he visto en la discusión de Bolonia es una pugna a veces obscena y caciquil por tener más asignaturas o más créditos para las propias. Es decir, una pugna de intereses. Muy excepcionalmente, he visto rasgos de honradez: no tenemos profesores suficientes, me dijo alguien un día, así que no podemos sobrecargarnos de asignaturas. $Y$ era alguien que enseñaba asignaturas importantes. Pero lo que no he visto en absoluto ha sido ninguna reunión ni seminario dirigido a reflexionar sobre qué 
tipo de jurista creemos que la sociedad del siglo XXI requiere. Y esto viene a cuento porque la sensibilidad de Josep M. VillajOSAnA (también la de José Juan Moreso en un mail que nos envió a propósito de ello) se inclina por un modelo en que se funden lo profesional y lo formativo. Es decir, por un modelo imposible en la mentalidad Bolonia. Para animar a la reflexión, sugiero que hemos de pensar en un jurista que cumpla en la sociedad que nos aguarda la misma función que cumple el médico en la salud de la sociedad y el arquitecto en el diseño del urbanismo y las ciudades. Un profesional que esté ubicado en el entramado social para informar y asesorar al ciudadano de la enorme cantidad de exigencias que le plantea ya hoy a cualquiera el orden jurídico. Y esto demanda de las Facultades de derecho un tipo de jurista que no se compadece nada con las premuras y rigideces de Bolonia. Valdría la pena que se pensara un poco en ello.

Andrea GREPPI orienta el comentario de algunas de mis posiciones desde el prisma de la separación de poderes. Me parece muy adecuado, aunque he de recordar que quizás el déficit más evidente de mi justificación del imperio de la ley sea precisamente el que se refiere a la panoplia de instituciones necesarias para mantenerlo en pie. Y uno de los principios institucionales evidentes para ello es el principio de la separación de poderes. No es este lugar, por supuesto, para entrar en la historia y el significado institucional de ese diseño institucional. Andrea lo hace muy bien. Lo que sin embargo sí me da la oportunidad de volver a decir es que el mundo de las reglas es particularmente idóneo y eficaz para hacer una cosa que los principios hacen con mucha más dificultad: atribuir poderes. He repetido una y otra vez que todo el discurso principialista y neoconstitucionalista gira en torno a normas de conducta pero tiene poco que decir en lo relativo a normas de competencia. No es que yo dude de que haya principios de competencia; puede haberlos (por ejemplo: «El gobierno dirige la política interior y exterior...»), pero hay que reconocer que las competencias se atribuyen mejor con reglas, y además, que así debe ser, porque organizada mediante principios la competencia pudiera dar lugar a situaciones difíciles, conflictos de competencia y frecuentes actuaciones ultra vires. Y eso puede ser un corolario importante de mi posición en favor del imperio de la ley. Andrea GREPPI lo intuye muy bien. «Los límites del ejercicio de la autoridad» — como él escribe- se establecen mucho mejor con un derecho de reglas. Y sobre todo, el ciudadano está mucho más amparado frente a las arbitrariedades del poder si el poder se regula y distribuye mediante reglas precisas. No sé si esto es estar «a la sombra de HOBBES»; me parece que no tanto, porque el principal problema hobbesiano es, creo, el de la ausencia de limitación del poder del Leviathan. Cuando Andrea trae a su texto, para finalizar, esta expresión mía no se da cuenta quizás de que yo la uso para hablar del derecho internacional y de la globalización. No tanto del imperio de la ley. En lo que a este respecta soy mucho más lockeano, pero el destino de una firme comunidad jurídica internacional pasa necesariamente por HOBBES.

Esto me da pie para enlazar con la excelente ponencia de Isabel TuRÉGANO. Isabel parece detenerse un poco ante la decidida posición «hobbesiana» que tenemos tanto Liborio como yo. Liborio se ha ocupado más de las posibilidades de una teoría seria de la justicia en un mundo global; yo por mi parte me preguntaba por la posibilidad del rule of law en el mundo globalizado, incluso en el mundo del derecho internacional. Que esa no era una pregunta impertinente lo demuestra que entre los objetivos del 
milenio de las Naciones Unidas se encuentre precisamente la implantación del imperio de la ley en las relaciones internacionales. Pero ambos, me parece, acabábamos en una hipótesis parecida: que es necesaria la implantación de una estructura jurídica institucional que administre el uso de la fuerza en la comunidad internacional. E Isabel nos recuerda que, por así decirlo, hay que ir paso a paso. Que hay que contar con estructuras de dominación muy complejas, que hay que tener conciencia de la pluralidad y la diversidad de relaciones y movimientos que ya están en marcha y están operando el altruismo internacional o transnacional. En fin, que hay que tener una percepción más particularista y menos cosmopolita o universalista. Isabel TURÉGANO parece echarnos un poco en cara, y seguramente con razón, que hayamos ido a caer en la llamada «analogía doméstica», es decir, en construir el espacio del derecho internacional con las mismas cuadernas que el derecho nacional o doméstico. De acuerdo con esa analogía, nuestra tarea actual sería la de erigir un estado internacional concebido con las coordenadas básicas del estado doméstico, y una democracia internacional «conforme al modelo de las democracias liberales nacionales». Isabel pone en cuestión esta argumentación tan lineal llamando nuestra atención sobre particularidades y consensos intermedios que pudieran dejarse de lado en una teoría abstracta como la nuestra. Por lo que a mí respecta (Liborio seguro que puede argüir de otra manera), mi respuesta sería que, si no estamos refiriéndonos a estrategias y procedimientos para alcanzar un objetivo dado (punto en el que seguramente Isabel TuRÉGANO tiene bastante razón) sino a una concepción previa del derecho internacional y del lugar del imperio de la ley en él, entonces me parece que la institucionalización internacional de una agencia con competencias normativas generales y administración de la coacción es condición necesaria para que podamos hablar del imperio de la ley en el ámbito internacional. Que llegar a esa agencia pueda hacerse con toda la complejidad de los procesos sobre los que Isabel llama nuestra atención es una cosa, que como concepción de las relaciones internacionales pueda ser sustituida por acuerdos particulares y consensos complejos es algo bien distinto. Como tantas otras veces, también me sucede con Isabel que estoy seguro de que estamos luchando por las mismas cosas, pero nuestros desacuerdos son mucho más cuestión de método o de concepción que cuestión de visión de la justicia. Lo que lamento es que no pueda corresponder adecuadamente en estas líneas a su rica intervención. Pero eso es algo que no excluyo para el próximo futuro, pues precisamente mi pesimismo hacia ese futuro me hace interesarme particularmente en esa disyuntiva.

Y respecto a la ubicación de mi teoría del imperio de la ley en el marco de la filosofía del derecho, creo que Alfonso García Figueroa no acaba de ser lo suficientemente fino en el análisis. El cree que el libro sobre el imperio de la ley tiene dos almas, pero no tiene nada más que una, el alma kantiana. En la primera parte de él explico por qué para vivir en sociedad es necesario un contexto normativo coactivo. Se trata de una consecuencia de la racionalidad de seres que quieren sobrevivir en su ambiente. Como en supuestos de dilema del prisionero la racionalidad de los actores les impele a una solución subóptima, acuden a un mecanismo de control normativo que mejora artificialmente su racionalidad. Puro HobBES. Pero esto, como es bien sabido desde siempre, deja el sistema de control en manos del omnipotente gobierno. Y ahí, y solo ahí, aparece como un ideal ético el imperio de la ley, entre cuyas funciones básicas se encuentra precisamente la de limitar el poder del Leviathan. Cómo se ve, no son dos 
almas, sino, por seguir con la manida metáfora, un cuerpo necesario (el del orden normativo) al que pueden atribuirse muchas almas (la mera seguridad, la igualdad, la libertad, etc.). El ideal kantiano, me parece, pretende asumir la existencia de ese cuerpo dotándole del alma innata de la libertad, y esto es el imperio de la ley.

Alfonso relata la práctica de algunos pueblos de Andalucía de limpiar la casa los sábados como muestra de que no respetaban el sabbath, es decir, de que no judaizaban. Le cuento otra paralela. En los altos de Granada y de Huelva se desarrolló en la misma época la práctica de colgar en el exterior de la vivienda, bien visibles, piezas de carne de cerdo, para poner así de manifiesto que sus habitantes consumían esa carne. Ello dio lugar a la curación particular del cerdo que se estila entre nosotros, y con ella al jamón ibérico. Puede decirse que es la consecuencia más benéfica que el género humano haya extraído nunca de un credo religioso. Alfonso sabe que yo no recurro al origen de la práctica del derecho (vaya usted a saber cuándo se origina esa práctica), sino a la explicación racional de la misma, lo que llama muy cultamente una ananké. El derecho aparece porque se quiere un fin, pero ese fin no es la autonomía personal, como él dice, sino la supervivencia personal. Si fuera la autonomía personal entonces habríamos salido del imperio hobbesiano y nos habríamos trasladado a la exigencia kantiana, y por tanto, no habríamos mezclado nada. Alfonso registra esto con claridad, lo que quizás hace a su argumentación contradictoria. Como hemos visto antes, la objeción de las dos almas no es pertinente. Ahora empieza otra, que parece dolerle más. Mi mensaje puede reformularse así: si nos alejamos de reglas precisas, nos complacemos en las indeterminaciones del discurso, no creemos en la posibilidad de una interpretación objetiva y concedemos al juez un margen amplio de decisión inspirada en principios, todo eso está suena muy bien pero nos fuerza a dejar de hablar de imperio de la ley, rule of law o Estado de derecho. Si eso es lo que queremos, hagámoslo, pero no sigamos hablando de esas cosas. Como lo sugiere muy bien Alfonso GARCía FiguEROA yo soy de los que creo que las reglas nos hacen más libres que los principios (también a él, en sus actos más cotidianos: introducir la llave en la cerradura de su coche, almorzar en un restaurante, cobrar su nómina, pagar sus impuestos, ir al teatro, vivir en su casa y educar a sus hijos). Sugerir que eso me identifica con el BENTHAM debelador de los derechos humanos me parece que no encaja. A lo mejor sí encaja que me identifique con su crítica del Common Law y del judicialismo. Estas últimas siempre me han parecido actitudes sensatas en su contexto histórico. Y lo que me parece un pequeño salto mortal con cierto riesgo es afirmar que la tradición kantiana ha servido de base al neoconstitucionalismo actual. Sobre eso nos tiene que dar más pistas.

Y si yo explico el «origen de mis desvelos» por el imperio de la ley por mis vivencias durante el franquismo, es precisamente por esas vivencias por lo que creo en el valor de nuestra Constitución, y no tanto por sus «principios iusfundamentales», como él dice (una dimensión de la que nadie, tampoco él, se percató hasta veinte años después de su vigencia), sino sobre todo porque con ella se terminó la arbitrariedad del tirano y empezó en una medida antes inédita el sometimiento del poder al derecho y con ello la libertad de los ciudadanos. Y eso se hizo con normas precisas que también eran preciosas.

Estoy, finalmente, de acuerdo con que nuestras instituciones no se pueden juzgar por el mal uso que se hace de ellas, y seguramente me he sentido más veces defrau- 
dado por la calidad deplorable de los fallos judiciales de lo que Alfonso pueda imaginar; también he notado la sensación de impotencia y abandono que experimentan los abogados todos los días por ello. Pero me parece que eso se puede detectar mejor y también combatir mejor desde una actitud legalista que desde la jurisprudencia de principios, porque, que no se engañe nadie, esas normas preciosas que tanto valora Alfonso GARCÍA FIGUEROA ponen un arma de gran peligro a disposición de jueces muy mal formados en la argumentación moral: una premisa mayor que parece evidente a primera vista pero que está aquejada de las complejidades del discurso ético hasta extremos que muchos no pueden ni siquiera percibir.

Dos colaboraciones que me satisface especialmente comentar son las de Ricardo GARCÍA MANRIQUE y Borja BARRAGUÉ sobre algunos extremos de nuestra posición ante los derechos sociales. Ricardo García MANRIQue es consciente de que este tema suscita pasiones profundas. Tuve la oportunidad de recordar en el seminario que el origen próximo de este ensayo mío sobre los derechos sociales está en una petición que me hizo Carlos NiNo de acudir a Buenos Aires en plena campaña por la reforma constitucional que él auspiciaba, porque - me decía- los peronistas pretendían constitucionalizar y hacer justiciable todo derecho social imaginable, y NINO pensaba, como yo, que eso era, en el mejor de los casos, una manera estúpida de crear expectativas masivas imposibles de cumplir. La compañía hizo de aquel viaje algo inolvidable: Ernesto GARZÓN VALDÉs, Francisco TOMÁs y VALIENTE y Juan Linz. Cuando acabé de presentar mi posición sobre el concepto de derechos sociales y la impertinencia de protegerlos simplistamente por la jurisdicción ordinaria, alguien al final del salón se levantó, dijo a grandes voces: «iun ataque demencial!» y se marchó. Presumo que sería un justicialista. Pero también hubo quien se entusiasmó demasiado con mi teoría de que la protección jurisdiccional excesiva interfería con el principio democrático. Fue Juan LiNZ, que lo llamó, quizás exagerando un poco, «el gran argumento». La gente detectó, pues, lo que yo pretendía, y Ricardo hace un excelente resumen de ello: en primer lugar, un ejercicio de clarificación conceptual, que acababa en una «demolición» de la diferencia entre derechos liberales y sociales, y en segundo lugar, llamar la atención sobre la imprudencia inútil de constitucionalizar demasiado intensamente esos derechos y conferir a los jueces la competencia para decidir sobre ellos, suponiendo que con ello se protegen más o mejor. En general, Ricardo se muestra de acuerdo pero tiene algún matiz que se expresa muy agudamente en dos preguntas que nos hace a los dos. La primera es que hay una mayor diferencia con los derechos liberales de la que yo al menos señalo, pues los derechos sociales «contienen expectativas muy amplias acerca de cómo han de organizarse procesos comunitarios básicos» como la educación, la sanidad, el trabajo, etc. Me parece que la respuesta a esta pregunta puede ser repensar cómo ha sido la historia de los derechos llamados liberales, para caer en la cuenta de que también han contenido expectativas enormes sobre cómo han de desarrollarse las pautas de convivencia. Y aún continúan haciéndolo. Sucede, sin embargo, que para fortuna suya y mía, hemos nacido en un tiempo y en una región en que muchos de ellos son ya derechos subjetivos muy consolidados y parece, por así decirlo, que han estado ahí siempre. Pero no hace tantos años no lo eran. Y no hay que olvidar por eso que también ellos tienen lo que Ricardo llama un «sentido político especial», si con ello quiere decir que están sujetos como los otros a deliberación y controversia. 
La segunda pregunta es más peliaguda: los derechos sociales tienen una evidente incidencia en el mecanismo del mercado. Aceptando que los derechos liberales no tengan tanta ¿no es esto una importante diferencia entre ambos? Ricardo llega a sugerir que la economía de mercado puede no ser compatible con la vigencia de los derechos sociales. Y pone como ejemplo paradigmático el derecho al trabajo. Porque, en efecto, si todos tuvieran derecho al trabajo y el trabajo no pudiera considerarse una mercancía sino un criterio fuerte de distribución, la economía de mercado se vería fuertemente afectada por ello. No puedo descender a elaborar una respuesta, aunque intuyo que es cierto que aquí habría una diferencia apreciable, al menos con algunos derechos liberales. La apunto solo: los derechos liberales tienen una relación privilegiada con el mecanismo del mercado, que consiste en que lo constituyen. La economía de mercado no existiría sino en expresiones muy limitadas si no se dieran en el derecho positivo los derechos de propiedad, la moneda legal, las libertades de intercambio y negociación, y la protección judicial de las transacciones. Los economistas han actuado muchas veces como si el derecho fuera una variable irrelevante en sus reflexiones, pero ya están entrando por el aro. Algunas libertades civiles son condición de posibilidad del mercado capitalista. Por eso, los neoliberales (que yo llamo «mercadistas») hacen tantas loas ahora a la libertad. Pero con la llegada de los derechos sociales esas libertades se ven condicionadas y limitadas. ¿Puede ser esa la diferencia? Prometo perseguir este tema.

Borja BARRAguÉ plantea interrogantes muy agudos sobre mi concepción de la igualdad material. También a él tengo que decirle que todo viene de más atrás. Espero que esto no se transforme en un conjunto de batallitas propias del jubilado. A finales de los ochenta del pasado siglo, Alfonso Guerra dio en organizar en Jávea con la revista Sistema una serie de coloquios sobre los problemas del socialismo, y en uno de esos coloquios se me invitó a poner de relieve los ingredientes ideológicos del socialismo y sus problemas (el coloquio se celebró en 1985 y apareció como libro con el título El futuro del socialismo, Madrid, Sistema, 1986). Fue entonces cuando planteé con seriedad ante un auditorio nada convencido, que la identidad material de recursos para todos y cada uno (es decir, la igualdad tal y como se veía en el imaginario socialista clásico) era un ideal que carecía de fundamento. Lo que sucedía, explicaba yo, es que en un mundo de escasez moderada o no tan moderada, si el socialismo quería luchar por la dignidad y la libertad de todos, tenía que asumir grandes dosis de igualdad. Lo que se buscaba, pues, no era la igualdad, sino un conjunto de bienes básicos que configuraban la dignidad y la autonomía de la persona, y sin los cuales esos ideales eran impensables. Pero como el socialismo actuaba en un mundo de escasez, tenía que promover criterios distributivos serios para alcanzarlos. De ahí que, aunque no la buscara, el socialismo «se tropezaba» con la igualdad. El supuesto que me plantea Borja es un supuesto, me parece, de escasez desmesurada: mil personas que necesitan al menos 10 unidades alimentarias cada una para sobrevivir, y tenemos solamente nueve mil unidades alimentarias. No me gusta el supuesto, porque me parece que desliza el escenario más allá de la justicia. Ninguna de las dos soluciones (que mueran todos o que muera solo el 10 por 100) puede justificarse sobre la base de un principio de justicia. Estamos más allá de ella: en la tabla de Carnéades. Trabajemos con un supuesto diferente: tenemos mil personas con las mismas necesidades (es decir, necesitan diez mil unidades alimentarias) y tenemos once mil unidades alimentarias. La pregunta es ¿se justifica en virtud del principio de igualdad material que distribuyamos a cada una de las mil personas once 
unidades? ¿Qué sucede con aquellos que han protegido la cosecha, con los enfermos, con los que han ideado el método de transporte, y con los que han entregado mucho más tiempo que los demás a la producción de las unidades? ¿Por qué han de recibir solo una unidad más? ¿Por exigencia de la igualdad? Y aquí venía mi conclusión: una vez satisfecha la cuota de bienes que configuran la dignidad de cada uno, entonces la igualdad queda desactivada como exigencia moral. Si a ello se añade que hay otros principios (el mérito, el sacrificio, la necesidad, el trabajo, etc.) entonces hemos de abandonar la igualdad como criterio distributivo. Lo que Borja parece sugerir, en un paper denso y difícil de recorrer en pocas líneas, es que, más allá de la satisfacción de las necesidades básicas que definen la dignidad de las personas, hay todavía una exigencia moral de igualdad, o una exigencia contra la desigualdad, porque esta tiene efectos sobre la movilidad social, los determinantes sociales de la salud, el movimiento sostenible, la capacidad de expresar las preferencias o la igualdad de oportunidades. Si una desigualdad material produce efectos evidentes en la capacidad de participar en las deliberaciones o en la situación que uno (o sus descendientes) ocupe en los puestos de salida, entonces es evidente que la desigualdad material es indeseable y que hay una exigencia de igualdad material que eluda esos hándicaps, pero creo que esto pudiera ser incluido en mi argumentación de modo relativamente sencillo. Si los que tienen más bienes tienen privilegios en la carrera, es preciso reforzar a los que tienen menos bienes. Si tienen más voz que los que tienen menos bienes, es preciso proporcionar a estos esa voz que les falta. Bien. Aunque esto, como RaWLS mismo señalaba, tiene algunos límites: no vamos a suprimir la familia porque los que se crían en familias ricas y cultas tengan más oportunidades. Y por lo que se refiere a lo segundo: la igualdad no se persigue, sino que se tropieza, me parece que Borja está de acuerdo, aunque, a diferencia del amor (y de los resultados que son un mero subproducto) hacer algo por obtenerla, o al menos por conservarla, no es del todo inútil.

Javier ANSUÁTEGUI escribe un ensayo muy amable sobre mi noción del imperio de la ley en el que hace observaciones interesantes la mayoría de las cuales he comentado antes, pero registro en él un error que me importa subrayar. Seguramente por culpa de mi escasa delimitación de las cosas, Javier extrae de mi libro la idea, y cito literalmente, de que afirmo que los requisitos del imperio de la ley y la misma idea del imperio de la ley «son una condición necesaria de la juridicidad: un determinado grado de cumplimiento de las exigencias del imperio de la ley es imprescindible no para la justicia del derecho, sino para su existencia misma». Y después argumenta, con razón, que «si el imperio de la ley tiene un valor moral y su existencia es imprescindible para el derecho... entonces el Derecho tiene un rasgo necesario que tiene que ver con su valor moral: estaríamos afirmando la relación necesaria entre el Derecho y la moral». Pues bien, como esto ha salido alguna otra vez, quiero subrayar que el error de Javier es el de suponer que yo he dicho en algún momento que el imperio de la ley es condición necesaria de la juridicidad. Esto no lo he mantenido nunca, al menos conscientemente, entre otras razones porque hubiera tenido que afirmar cosas inimaginables, como que el derecho romano o el derecho indígena no eran derecho puesto que no cumplían con esos requisitos. No. Siempre he insistido en que el ideal del imperio de la ley era un ideal moral anterior al derecho, o si así lo prefiere, no se refiere al derecho que es sino al derecho que debe ser. Escuche Javier el viejo eco, aunque todavía sonoro, de Elías DíAZ: «No todo Estado es Estado de Derecho». 
El ensayo de Ricardo Cueva se centra en un tema que, como he dicho, solo colateralmente abordo yo, como es el de la división de poderes, pero no sé si lo enfocamos de la misma manera. Sus enfoques históricos son muy interesantes pero siempre están a punto de trasladar al pasado categorías que manejamos y definimos en el presente, reinterpretando así la historia desde nuestra mirada teórica. Lo que yo entiendo por división de poderes es, sustancialmente, que los poderes de emitir normas jurídicas estén sometidos a un control normativo independiente. Si el Legislativo sobrepasa los límites constitucionales, es controlado por un órgano ad hoc. Si el Ejecutivo sobrepasa los límites de la ley, existe un orden jurisdiccional independiente para corregirlo. Todo ello son mecanismos institucionales importantes que se inspiran en, y tratan de realizar, algunos principios del imperio de la ley, en especial el desiderátum del control del poder por el derecho. Solo se somete al derecho el poder si existen esos mecanismos institucionales que configuran separada e independientemente los poderes. Me parece que Ricardo entiende por división de poderes otra cosa que, dice, es constitutiva del gobierno democrático. Cuando dice que «todo sistema democrático exige división del poder (territorial o de otros tipo...) (las dos cursivas son suyas), y añade que lo que hay que evitar es «el gobierno de facción, de un grupo hegemónico de intereses que socave el bien común», me parece que está haciendo referencia más bien a algo parecido a esa aspiración de parte de la teoría política americana a que el poder social se halle dividido, atomizado si es necesario, de forma que ningún poder pueda imponerse a otro. Lo que alguno de esos autores ha llamado la poliarquía, como requisito para la democracia. DAHL, por ejemplo, afirma que sin una división previa del poder social es difícil que no haya tiranía. Esto está bien, pero tiene poco que ver con la teoría de la separación de poderes.

No pienso mostrar a Joaquín ALMOGUERA ningún «distante agradecimiento» sino uno genuino y cercano. Son ya muchos años y muchas conversas. Su contribución me parece sugestiva pero también familiar. Me suena familiar el recuerdo del horrible althusserismo del medio ambiente en que nos conocimos. En nuestro departamento, afortunadamente, eso no penetró. CERRONI, su CERRONI, era otra cosa. Y en el plano personal me suena familiar sobre todo la angustia almogueriana por el número de páginas, que va recorriendo los párrafos del escrito. Cuando le quedan 768 palabras empieza con ROUSSEAU, es decir, empieza con el tema que me es más sugerente. Lo anterior es una densa explicación histórica que valdría la pena que desarrollara sin la espada de Damocles del número de páginas. Pero Joaquín adivina que después de mi imperio de la ley está la pregunta por el legislador, está lo que en expresión feliz llama «la construcción del legislador». Aquí desemboca su ponencia, o mejor dicho, aquí desemboco yo mismo, con algunos acercamientos anteriores esporádicos a problemas de técnica legislativa y a preguntas por la representación política. Pero lo que está después es, en efecto, la construcción del legislador democrático, un tema bastante abandonado en el seno de una barahúnda inmensa de escritos y debates sobre la teoría de la democracia.

Si le he entendido bien, Mariano MelERo sugiere también que separo demasiado los aspectos éticos del imperio de la ley de la idea del derecho que tengo. Aunque él parece dudarlo, yo creo que puede distinguirse bien un orden jurídico configurado conforme a las exigencias del imperio de la ley de la mera legalidad vigente. Distingo entre el «ser» del derecho y el «deber ser» del derecho, y eso me parece muy plausible 
(de hecho observo que lo hacemos todos los días en cuanto nos enfrentamos a una nueva ley o sentencia), e identifico el «ser» del derecho mediante una observación de sus fuentes sociales, y el «deber ser» del derecho con una apelación a criterios morales. Mariano sugiere que debe haber alguna conexión entre ambos mundos, y para ello se fija en la necesidad de la argumentación y del due process. Y en efecto, si exigimos una argumentación racionalmente contrastable para la interpretación y la aplicación de todo derecho, entonces la existencia misma del derecho tendrá una dimensión ética. Pero yo no cedo a esa tentación. El «car tel est notre bon plaisir» de los monarcas Capetos creaba derecho tanto como el Parlamento de Westminster, y no parece que sea una argumentación nada seria. Y al «debido proceso» le sucede lo mismo. Si lo entendemos como un conjunto de requisitos para que la decisión judicial exista, entonces mezclamos los planos del ser y del deber ser, pero si aceptamos que una decisión tomada por un juez venal a cambio de algún favor y sin oír a ambas partes, sigue siendo una decisión judicial, entonces no lo hacemos. Naturalmente que con las exigencias morales del debido proceso y la justicia natural se protege más la autonomía personal, pero es que tales exigencias se sitúan en el plano ético del imperio de la ley.

Me importa mucho comentar las ideas de Cristina García Pascual porque me parecen sustancialmente correctas pero ella cree que no las comparto. Reivindicar hoy el derecho internacional me parece una necesidad tan imperiosa que intuyo que la posibilidad de futuro de la convivencia humana depende de ello. El dilema de Koskenniemi me parece, como todo en él, un tanto sobreactuado. Pero si hubiera de sentirme atrapado en tal dilema (o ser realista apologeta del poder, o ser utópico ético irrelevante) seguramente preferiría esto último, o trataría de zafarme a través de una posición ética coherente y seria. Me parece que adoptar una actitud ética ante las relaciones internacionales no es irrelevante. Al menos traslada la carga de la prueba al «realista».

Me parece que el error de Cristina proviene de una posición que me atribuye como propia aunque no pretendía ser sino una descripción del panorama de la teoría de las relaciones internacionales. Cristina parece creer que pienso que el derecho internacional ha sido superado por el derecho llamado global, por la globalización jurídica. Ni mucho menos. Yo me limité a constatar que en la literatura sobre el tema se afirma que la globalización ha traído un derecho diferente del derecho internacional, con instrumentos normativos diferentes y diferentes modos de actuar. Y desde luego soy escéptico frente a él. Creo que en gran medida es todavía un espejismo (quizás solo hay globalización financiera y globalización cultural) y está todavía sin regular satisfactoriamente, es decir, no tiene un alcance jurídico mínimamente sólido. No hay más que ver el Handbook of Transnational Governance editado por Thomas HaLE y David HELD en 2011 para ver lo enclenque y meliflua que es esa regulación. Siempre he sido cauteloso con la gran eclosión que hay de verborrea globalizadora, aunque la globalización es un fenómeno que no hay que ignorar. Y, como Cristina sabe, soy reticente ante los instrumentos normativos que propone ese fenómeno: networks, gobernanza y soft law. Mi posición es más bien la de apoyar procesos como la Unión Europea, en los que los estados ceden deliberadamente competencias normativas y se someten a normas supranacionales con órganos judiciales supranacionales, y la de fomentar, desde luego, lo que en teoría de las relaciones internacionales se llaman «regímenes internacionales», que vienen a ser tratados internacionales sobre objetos sectoriales 
entre países interesados. Y, por supuesto, seguir reforzando a la Organización de las Naciones Unidas como depositaria de un derecho realmente internacional. Seguro que en los pasillos y las habitaciones de esos edificios nos encontraremos Cristina y yo con mucha frecuencia ${ }^{3}$.

En conexión con ello, las ideas que aporta Agustín MENÉndEZ me parecen extremadamente interesantes. No me siento competente para acompañar con detenimiento a Agustín por los meandros de la realidad jurídica y política de la Unión Europea. Me faltan conocimientos para ello, pero la línea que apunta de construcción de una realidad política que tiende al constitucionalismo democrático me parece muy afín. Y me interesa mucho lo que intuyo de su opinión sobre las dificultades para realizar una construcción semejante apoyándose en las coordenadas del neoconstitucionalismo. Hago mío también el temor que se trasparenta en su ensayo por la mutación del derecho de la Unión Europea. Ya había leído algún artículo suyo muy demoledor sobre el tema. Retazos de ese temor están llegando sin duda a los ciudadanos de la Unión, y temo que las cosas no estén mejorando nada últimamente. A mi juicio, la construcción europea como organización política y jurídica supranacional sufrió un revés serio cuando se malogró la llamada Constitución Europea. Entonces propuse algo que ahora puedo ver reflejado en el artículo de Agustín: reconducir los estúpidos referéndums que echaron a perder aquel proyecto a unas elecciones serias al Parlamento europeo, es decir, promover el constitucionalismo democrático en Europa. Me alegro de coincidir con él.

El ensayo de Massimo LatorRe, en lo que a mí concierne, resulta un tanto desorientador, y me ilumina poco por muchas luces que trate de proyectar sobre él con su batería de citas eruditas. ¿Qué tendré yo que ver con ROSENZWEIG o Joseph WEILER y sus peroratas religiosas sobre la pureza moral? Nada. Me parece, por el contrario, que me enfrento con razonable cuidado a la paradoja de la autoridad: si hay ley no hay autonomía, si hay autonomía no hay ley. Por otra parte, no hay que retrotraerse a los lejanos análisis normativos de LABAND para saber que las prescripciones (no solo las leyes) tienen un carácter deóntico y un contenido; eso es lo que las hace prescripciones. $\mathrm{Y}$ es obvio que todo un orden construido con los ingredientes del imperio de la ley puede venirse abajo si la sociedad en la que tiene vigencia abandona sus convicciones al respecto e ignora a sus enemigos. Eso es un límite sociológico a la existencia del rule of law, de la democracia y de los derechos fundamentales, y parece tan obvio que no vale la pena acudir a ejemplos históricos. Para que la ley limite al poder soberano tiene que darse en esa sociedad la práctica social de adherirse a ciertas exigencias, y reaccionar cuando esas exigencias se incumplen. Seguro que Massimo recuerda el conjunto de claudicaciones sociales que determinaron el ascenso de Mussolini o de Hitler al poder.

Por otra parte, no recuerdo haber escrito en ningún lugar que la ley esté por encima de la Constitución. Ni tengo que replantearme mi iuspositivismo si para definir alguna propiedad moral del imperio de la ley recurro a los desiderata de FulLER: le recuerdo que no estamos describiendo el derecho (como sí lo pretendía el propio FU-

3 En plena redacción de estas notas me llega el número del 2016 de Teoría Política en el que hay un artículo mío: «El pacifismo jurídico y la teoría del derecho internacional», con unas críticas de G. ITZCOVICH. Seguro que le ayuda a reconciliarse conmigo. 
LLER), sino explicitando los requerimientos del rule of law. Recordará seguramente Massimo que también lo hace RAWLS para configurar las restricciones formales del concepto de lo moralmente recto. $\mathrm{Y}$ en general no me paro a considerar la posición política de quien propone una idea. Eso me parece una variante del argumento ad hominem, que, como es sabido, es inconcluyente. $\mathrm{Y}$ así, puedo resultar convencido por Adrian VERMEULE respecto a las consecuencias empíricas del literalismo, pero no por su posición sobre las relaciones internacionales; o por Antonin SCALIA en teoría de la interpretación pero no en tantas otras cosas. No digo que pase, pero puede pasar. $Y$ por fin, no acabo de entender muy bien por qué mis precauciones con lo que se ha llamado «sobreconstitucionalización» deben necesitar como una suerte de terapia abrazar la teoría del discurso habermasiana o al segundo RAWLS. Puedo mantenerme en la idea de que el alcance de la Constitución y el de la ley han sufrido en estos años un cambio que me parece inconveniente. Hace ya tiempo, un magistrado del Tribunal Constitucional me contaba que un ama de casa había podido llegar al Tribunal con un recurso de amparo porque la vecina de arriba colgaba su ropa mojada y goteaba sobre la suya. Naturalmente, el caso no tenía pies ni cabeza, pero lo alarmante es que alguien pudiera apelar a la Constitución en tal supuesto.

Silvina Álvarez ha sido, desde que se incorporó a nuestra Área, una colega inestimable. Formada con Carlos NiNO, ha seguido con gran rigor la estela de su elaboración teórica de los derechos humanos y se ha unido con facilidad y altura a los cursos ordinarios de derechos humanos que impartíamos en ella. No es extraño por tanto que nos invite a seguir pensando en ellos. Y con una propuesta estimulante. Si yo la interpreto bien me parece que quiere invitarnos a que ampliemos nuestra visión de los sujetos de los derechos, desde la construcción abstracta de un destinatario «sin atributos», por así decirlo, hacia una consideración más específica de las relaciones y situaciones en las que se encuentran algunos de esos sujetos, en particular, naturalmente, las mujeres. Es obvio que cuando aparecen los derechos humanos y el sufragio «universal», el sujeto abstracto de los derechos y del ideario liberal no lo era tanto; se trataba de los muy concretos hombres propietarios con exclusión de las mujeres. Por eso, esa demanda de tomar en cuenta aspectos sustanciales — no tan «neutrales»— que estén en la base de la titularidad de los derechos me parece atendible. La discriminación y exclusión de la mujer - lo tengo escrito — no es una injusticia cualquiera; es seguramente la gran injusticia que ha cometido la especie humana contra sí misma. Y reparar esa injusticia tiene que exigir abrir el campo de comprensión del discurso de los derechos de forma que asuma las situaciones culturales y sociales en las cuales la mujer se halla en una situación de dominación carente de fundamento. Puede exigir, en fin, que el discurso de los derechos se enfrente directamente con ese diseño a priori del mapa social y económico que determina que, por muchos que sean sus derechos en abstracto, la mujer encaje predominantemente en una posición subordinada. Querida Silvina, acepto tu invitación con mucho gusto.

Rafael ESCUDERo suscita uno de los problemas que, por así decirlo, están fuera de los circuitos frecuentados por los demás. Se trata de mi posición en torno a la reforma constitucional. Me alegra que lo traiga a colación porque es un tema sobre el que vengo avisando desde hace ya muchos años sin grandes resultados. Y tiene razón: no se trata de un tema de filosofía de la reforma constitucional sino de una aproximación pura- 
mente interpretativa a dos preceptos de la Constitución. En el trasfondo sin embargo, hay una opción tácita en favor de una razonable flexibilidad de las constituciones. En 2004 ya advertí que algo había que hacer en este tema porque la rigidez de la Constitución iba a acabar trocándose en rigor mortis. RUBIO LLORENTE, no hace mucho, recurría a la misma metáfora: rigidez y rigor mortis (Claves, núm. 241, agosto de 2015). La legislatura pasada me permití volver a urgir la reforma. Pero era impensable que el Partido Popular tomara la iniciativa: en la legislatura anterior había boicoteado la propuesta del Gobierno de Rodríguez Zapatero ampliamente estudiada por el Consejo de Estado, y en la legislatura siguiente, con mayoría absoluta, se sentían los reyes del mambo y se limitaron a olvidar el tema. Y en esto llegan las elecciones de diciembre de 2015 y cambia el panorama del Congreso de los Diputados dramáticamente. La consecuencia de esa estúpida posición es que, hoy por hoy (escribo en febrero de 2017), toda reforma constitucional va a verse forzada a dos cosas: un consenso mucho más amplio que el anterior, y la celebración casi necesaria de un referéndum. Como no se va a producir ninguna de las dos cosas, la Constitución se va a deteriorar seriamente, si es que no lo está ya. Desde luego, el llamado sentimiento constitucional no levanta cabeza. Ya estamos pasando de la rigidez al rigor. Pero en cuanto a los dos preceptos se refiere, admito que hay argumentos nada desdeñables contra la interpretación formalista del primero y su aplicación al segundo, aunque me parece que las razones para negarlo son mucho más oscuras que las razones para afirmarlo, que pueden presentarse limpiamente desde la lógica más estricta. Pero la interpretación estricta que yo proponía del 168 me parece bien fundada, tanto en la elaboración de la Constitución como en la semántica más pura que quepa imaginar. Pero me parece que todo esto está empezando a ser ya una variante del llorar por la leche derramada. Y la excesiva rigidez, que parece ser la apuesta de Rafael, una suerte de suicidio constitucional. Y a mí eso me pesa.

Ya he tenido la oportunidad de decir alguna vez que admiro mucho a Félix OvEJERO. Me parece ser uno de los pocos bastiones desde los que la racionalidad habla claramente en Cataluña. Es como el niño que grita que el rey está desnudo. Y dado que tanto en el cuento de Andersen como en Cataluña, el rey está en realidad desnudo, la voz de Félix resulta impagable. A lo mejor esta coincidencia mía con él se deriva, como afirma, de que no soy nada nacionalista, y el relato nacionalista es precisamente el traje nuevo del emperador. Y dado que no soy nacionalista, tampoco soy españolista. Se me antoja, desde luego, que las sociedades han de tener un modo común de articulación para ser tales. Pero tengo muchas dudas sobre la naturaleza de ese vínculo común. En todo caso no participo en absoluto del mito del carácter nacional. Y menos en los tiempos que corren. Los arquetipos nacionales no son más que tópicos y prejuicios (en pro y en contra). Y eso de que hay una colectividad de personas que «quiere ser», me parece muy poético pero carente de significado. No sé si eso me trasladará desde mi inicial y vocacional a-nacionalismo al anti-nacionalismo, pero desde luego me parece muy necesario recordar incesantemente algunas cosas de los nacionalistas: la primera de ellas es que, digan lo que digan, secretan lo que Luis RoDRíGUEZ ABASCAL ha llamado «fronteras interiores», es decir, actitudes de discriminación implícita hacia los que no son nuestros nacionales. Si uno se identifica moralmente por su pertenencia al grupo, los que no son de aquí tienen otra identidad moral. A partir de ahí, vienen otras muchas cosas, algunas de ellas, y según quien mantenga esa actitud, tremebundas. Pero 
hasta las menos lesivas determinan que un medio ambiente nacionalista exija de quienes lo ponen en cuestión actitudes heroicas. Este es el caso de Félix, que seguramente está destinado a no ser catedrático en Cataluña, aunque su curriculum sea muy superior al de tantos. Pero él carece del supuesto nimbo moral que adorna las cabezas de los autóctonos. Como es sabido las acciones supererogatorias no son debidas, y seguramente por eso son admirables. Félix, desde luego, merece toda nuestra admiración.

Siempre me ha sorprendido una idea que me parece esconder una contradicción, y me aprovecho del artículo de nuestro querido Julián SAUQuiLlo para traerla aquí ahora. Porque creo que esa posición la mantiene también Julián. Hay algunos historiadores «posmodernos». En los últimos años han proliferado. Lo que añade a los historiadores eso de ser «posmodernos» es que piensan que es imposible retrotraerse a tiempos anteriores porque nos faltan las herramientas epistémicas para conocer y penetrar el significado de los hechos y las palabras de esos tiempos. Lo que me sorprende de esos historiadores es que no cambien de profesión. Afortunadamente, Julián no es historiador, porque también mantiene que, cito, «nadie puede trascender el presente para desentrañar con certeza el pasado. Pretender adentrarse en el túnel del tiempo con billete de regreso en tan difícil como saltar por encima de nuestra propia sombra». Ahora bien, Julián, que no es estrictamente hablando un historiador, es sin embargo un gran erudito y conocedor de la historia del pensamiento, de los clásicos. Y a ese respecto me pregunta — se pregunta - qué diálogo mantengo yo con los clásicos. Me complace mucho responder a esa pregunta (para después devolvérsela yo a él). Veamos. Para mí «clásico» no puede significar otra cosa que «vivo». Los clásicos son clásicos porque están vivos; lo son porque de algún modo nos interpelan, nos preguntan, nos provocan. Es decir, transmiten con sus palabras ideas, problemas, afirmaciones que hoy parecen servirnos en nuestra peripecia actual. Y ¿cómo podría esto tener lugar si ellos no se dirigían a nosotros y nosotros — según tantos hoy- no podemos entenderlos? ¿Cómo es que algunos de ellos nos alcanzan, nos vulneran, y otros que escribieron en sus días no lo hacen, es decir, no son considerados clásicos sino simplemente piezas arqueológicas para el especialista? Y la pregunta que es talón de Aquiles para tantos escépticos: ¿Cómo podemos saber que no los entendemos? Al contrario de esto, a mí me parece que los entiendo, y sobre todo me parece que ellos me entienden a mí de una manera profunda y especial, que conocen mis preocupaciones y mis experiencias con una luminosidad y un rigor fulgurantes. Creo que Julián tendrá que enfrentarse alguna vez con estas preguntas, si es que quiere seguir frecuentando a los clásicos.

Al final de su escrito, Julián afirma que hoy en día tiendo a confiar más en la fortaleza de las instituciones que en la reforma educativa. Esto no es del todo así. Las instituciones no son más que entramados de normas para alcanzar fines y resolver problemas. Si lo hacen razonablemente bien, son indispensables en cualquier comunidad. Si los miembros de la comunidad no confían en ellas, sucede lo que ya decía Maquiavelo (si es que podemos entenderle): «Y cuando la suerte hace que, como a veces ocurre, el pueblo no tenga fe en nadie al haber sido engañado antes, o por las cosas o por los hombres, se dirige necesariamente a la ruina» (Discorsi, L. I, $\$ 53$ ). Respecto a la educación, sigue pareciéndome una condición necesaria de todo proceso civilizatorio, y en particular del proceso democrático. Pero no es una condición suficiente. Creo recordar que fue Ernesto SÁBATO el que advirtió contra el exceso de confianza 
en la educación. Si los seres humanos son malos, decía, peor serán cuanto más sepan. $\mathrm{Y}$ educar en las virtudes es algo que tiene una merecida mala fama. Sin embargo yo sigo creyendo que lo peor que puede darse en una sociedad es la ignorancia, y más en sociedades ricas como la nuestra, en las que la ignorancia es arrogante y osada.

Y como colofón, la idea brillante de Ramón VARGas MACHUCA: el valor epistémico de la amistad. Cualquier cosa que suponga Ramón haber aprendido de nosotros no tiene comparación con todo lo que se aprende rodeado de amigos y colegas sabios y desprendidos como él y los que han protagonizado estas páginas. Por eso es tan estúpido y corto de vista el narcisismo de tantos profesores de universidad. Porque lo que sabemos, como dijeron también GINER y MACHADO, y tantos otros, lo sabemos entre todos. De ahí que tengamos que ser desinteresados y abiertos, porque cuanto más pongamos nuestras ideas a disposición de los demás, más sabremos nosotros. El valor que tiene el gran gesto de prodigalidad que ha tenido con nosotros Ramón y todos nuestros amigos y colegas al participar en este homenaje, no lo tiene tanto por lo que nuestras ideas puedan valer, sino porque con él se han entregado a un ejercicio colectivo de reflexión y conocimiento que constituye todo un ejemplo de vida universitaria con el que todos hemos aprendido más.

Y hablando de amistad, no puedo terminar sin enviar un abrazo a dos colegas y amigos en sentido fuerte: me refiero a Pablo DE LORA y a Jorge MALEM. Por gratitud y por justicia he tratado de hacer alguna observación, por desmadejada que fuera, a todos los que han enviado sus pequeñas observaciones, pero ellos — ibenditos sean! no han hecho ninguna observación a mis ideas, sino a las de Liborio. Esa es la razón de que les envíe solo un abrazo, pero ellos tienen que saber que un buen abrazo es tan valioso como la mejor de las cogitaciones académicas. Un abrazo para ellos y para todos los demás. 